\title{
WHY EMPLOYEES DO BAD THINGS: MORAL DISENGAGEMENT AND UNETHICAL ORGANIZATIONAL BEHAVIOR
}

\author{
CELIA MOORE \\ London Business School \\ JAMES R. DETERT \\ S.C. Johnson Graduate School of Management \\ Cornell University \\ LINDA KLEBE TREVIÑO \\ Smeal College of Business \\ Pennsylvania State University \\ VICKI L. BAKER \\ Albion College \\ DAVID M. MAYER \\ Stephen M. Ross School of Business \\ University of Michigan
}

\begin{abstract}
We examine the influence of individuals' propensity to morally disengage on a broad range of unethical organizational behaviors. First, we develop a parsimonious, adult-oriented, valid, and reliable measure of an individual's propensity to morally disengage, and demonstrate the relationship between it and a number of theoretically relevant constructs in its nomological network. Then, in 4 additional studies spanning laboratory and field settings, we demonstrate the power of the propensity to moral disengage to predict multiple types of unethical organizational behavior. In these studies we demonstrate that the propensity to morally disengage predicts several outcomes (self-reported unethical behavior, a decision to commit fraud, a self-serving decision in the workplace, and supervisor- and coworker-reported unethical work behaviors) beyond other established individual difference antecedents of unethical organizational behavior, as well as the most closely related extant measure of the construct. We conclude that scholars and practitioners seeking to understand a broad range of undesirable workplace behaviors can benefit from taking an individual's propensity to morally disengage into account. Implications for theory, research, and practice are discussed.
\end{abstract}

A host of ethical debacles across a wide range of contexts has inspired growing interest in studying and understanding why individuals engage in the kind of behavior that leads to enormous costs-trillions

Correspondence and requests for reprints should be addressed to Celia Moore, London Business School, Regent's Park, London NW1 4SA, U.K.; cmoore@london.edu. 
of dollars annually-for organizations and society. As just one example, the Association of Certified Fraud Examiners recently estimated that businesses globally suffer annual losses of $\$ 2.9$ trillion as a result of fraudulent activity (2010). This is a huge sum, indicating that unethical behavior is far more widespread than suggested by the intense focus on the few high-profile scandals that are covered by major news outlets. Thus, being able to better understand and predict who is likely to engage in such behavior - that is, behaviors within organizations that directly cause direct harm to another individual or that violate widely accepted moral norms in society-is crucial for organizational leaders and for societal well-being.

Organizational scholars have begun to identify a number of important contextual drivers of unethical organizational behavior, such as ethical leadership (Brown \& Treviño, 2006), ethical climate (Mayer, Kuenzi, \& Greenbaum, 2009), and codes of conduct (Weaver \& Treviño, 1999). However, research thus far has failed to explain a substantial proportion of the variance in unethical organizational behavior using contextual variables alone (Kish-Gephart, Harrison, \& Treviño, 2010). A range of individual-level factors has also been used to aid in the explanation of why people engage in unethical organizational behavior. The list of these antecedents is long, including Machiavellianism (Christie \& Geis, 1970; Shultz, 1993; Siegel, 1973), moral identity (Aquino \& Reed, 2002; McFerran, Aquino, \& Duffy, 2010), cognitive moral development (Ambrose, Arnaud, \& Schminke, 2008; Greenberg, 2002; Kohlberg, 1969), moral philosophies (Bird, 1996; Forsyth, 1980), empathy (Davis, 1983; Gino \& Pierce, 2009), and moral affect (Eisenberg, 2000; Paternoster \& Simpson, 1996; Tangney, 1990). However, effect sizes for their role in predicting unethical workplace behavior are generally small, leaving much variance unexplained (Kish-Gephart et al., 2010).

In this paper, we propose that an important additional driver of unethical behavior is an individual's propensity to morally disengagethat is, an individual difference in the way that people cognitively process decisions and behavior with ethical import that allows those inclined to morally disengage to behave unethically without feeling distress (Bandura, 1990a, 1990b, 1999, 2002). Broadly speaking, we know that how individuals processs, frame, or understand information relevant to ethically meaningful decisions plays an important role in their ethical and unethical choices (Kern \& Chugh, 2009; Tenbrunsel \& Messick, 1999), and recent reviews of the behavioral ethics literature have suggested that scholars should attend more carefully to the role of cognitive processes in unethical behavior (Tenbrunsel \& Messick, 2004; Tenbrunsel \& SmithCrowe, 2008). In the set of studies reported here, we heed these calls by 
establishing a new measure of the propensity to morally disengage as a uniquely important predictor of a broad range of unethical behaviors.

This research makes two major contributions. First, though there has been a surge of interest in the concept of moral disengagement in the past decade or so, researchers have not yet offered the field a carefully validated, parsimonious, and easily administered measure of the general propensity to morally disengage. To date, studies of moral disengagement have depended on idiosyncratic methods of assessment, with new measures employed for each study, often without systematic development (e.g., Detert, Treviño, \& Sweitzer, 2008; McFerran et al., 2010) or without tapping the construct in a comprehensive way (Aquino, Reed, Thau, \& Freeman, 2007). A number of scholars have designed measures with a specific audience in mind, such as children (Bandura, Barbaranelli, Caprara, \& Pastorelli, 1996), athletes (Boardley \& Kavussanu, 2007; Corrion, Scoffier, Gernigon, Cury, \& d'Arripe-Longueville, 2010), computer hackers (Rogers, 2001), or racial minorities (Pelton, Gound, Forehand, \& Brody, 2004), or with a specific outcome in mind, such as support for military force (McAlister, 2001), the death penalty (Osofsky, Bandura, \& Zimbardo, 2005), or violating one's duties to civic society (Caprara, Fida, Vecchione, Tramontano, \& Barbaranelli, 2009). Our first goal is thus to provide a measure that can be easily administered and used generallythat is, with any adult sample in any type of context (though we focus here on the workplace context) — to successfully predict a wide set of unethical behaviors. In doing so, we address a long-standing concern among organizational ethics scholars about the lack of valid and reliable scales to use in research (Mayer et al., 2009; Tenbrunsel \& Smith-Crowe, 2008; Treviño, Weaver, \& Reynolds, 2006).

Second, research on moral disengagement has often been conducted without an adequate understanding of its role within the existing landscape of individual predictors of unethical behavior. We thus propose how the propensity to morally disengage should relate to other individual difference constructs of three specific types: (1) morally revelant personality traits, (2) moral reasoning abilities and orientations, and (3) dispositional moral emotions. We empirically position the propensity to morally disengage within the landscape of these other constructs and demonstrate that, compared to them, it is a more powerful predictor of four different measures of unethical organizational behavior. Finally, given the strength of the propensity to morally disengage as a predictor of unethical behavior, and the fact that most studies with other individual difference predictors have not included a strong overarching theoretical framework, we suggest that researchers consider adopting Bandura's (1986) theory of self-regulation as a conceptual framework that may lead to better 
understanding of how these individual differences operate and collectively explain unethical behavior.

In what follows, we present the rationale and results of five studies that build on and complement one another. We used Study 1 to develop and establish the baseline psychometric properties of a parsimonious, general measure of the propensity to morally disengage. Then, in each of Studies $2-5$, we used an array of unethical behavior measures as dependent variables (measured independently from the propensity to morally disengage in each case) to test the general hypothesis that the propensity to morally disengage will explain a significant proportion of the variance in unethical organizational behavior after controlling for other variables within its nomological net. The alternate predictors included here are among the most theoretically relevant and among the most common individual differences used in ethical decision-making studies. However, they are almost never studied together nor are they adequately controlled for (as we do here) when demonstrating the utility of an additional construct. As part of this endeavor, we also show the superior ability of our new measure to predict both supervisor and coworker reported employee unethical behavior over the most relevant extant measure of the propensity to morally disengage in the workplace (McFerran et al., 2010). Together, these studies offer robust evidence of the power of an individual's propensity to morally disengage to predict a host of unethical behaviors of interest to organizational scholars and leaders.

\section{Theoretical Background}

Albert Bandura introduced the theory of moral disengagement as an extension of his more general social cognitive theory (Bandura, 1986: 375-389). According to social cognitive theory, when self-regulatory capabilities are working properly, transgressive behavior is deterred through the self-condemnation individuals anticipate they would suffer were they to engage in behavior that conflicts with their internalized moral standards. Moral disengagement theory explains how this self-regulatory process can fail when moral disengagement mechanisms disable the cognitive links between transgressive behavior and the self-sanctioning that should prevent it (Bandura, 1986: 375-389, Bandura, 1990a, 1990b, 1999, 2002). The moral disengagement process is theorized to play an important role in explaining how individuals are able to engage in human atrocities such as political and military violence (Bandura, 1990a, 1990b) or corporate wrongdoing and corruption (Bandura, Caprara, \& Zsolnai, 2000; Brief, Buttram, \& Dukerich, 2001; Moore, 2008b) without apparent cognitive distress. 


\section{Moral Disengagement Mechanisms}

Bandura proposed that moral disengagement occurs through a set of eight interrelated cognitive mechanisms that facilitate unethical behavior. Moral justification, euphemistic labeling, and advantageous comparison are three mechanisms of moral disengagement that serve to cognitively restructure unethical acts so that they appear less harmful. Moral justification cognitively reframes unethical acts as being in the service of a greater good. Illustrations include the justifying of military atrocities as serving a worthy goal (Kramer, 1990; Rapoport \& Alexander, 1982) or the recasting of inappropriate behavior such as unfair treatment as appropriate to protect friends or an organization. Euphemistic labeling is the use of sanitized language to rename harmful actions to make them appear more benign (Bolinger, 1982). For example, in corrupt organizations, those who collude are often positively labeled "team players" (see Jackall, 1988: 52-53). Advantageous comparison exploits the contrast between a behavior under consideration and an even more reprehensible behavior to make the former seem innocuous (Bandura, 2002). For example, misrepresenting small lies on expense reports can be viewed as more acceptable when compared with more egregious expense report violations.

The displacement and diffusion of responsibility mechanisms obscure the moral agency of the (potential) actor. Displacement of responsibility refers to the attribution of responsibility for one's actions to authority figures who may have tacitly condoned or explicitly directed behavior (see Kelman \& Hamilton, 1989; Milgram, 1974; Sykes \& Matza, 1957). Diffusion of responsibility works in a similar way but refers to dispersing responsibility for one's action across members of a group (see the description of the lead-up to the Challenger disaster recounted by Vaughan, 1996).

Distortion of consequences, dehumanization, and the attribution of blame mechanisms serve to reduce or eliminate the distress one perceives to be causing a victim (Sykes \& Matza, 1957). Distortion of consequences describes the minimization of the seriousness of the effects of one's actions, thus providing "little reason for the self-censure to be activated" (Bandura, 1999b: 199). This is illustrated by descriptions of stealing from a large, profitable organization as a "victimless crime" (Benson, 1985). Dehumanization is the framing of the victims of one's actions as undeserving of basic human consideration. This is fostered by defining others as members of an outgroup who are unworthy of moral regard (Deutsch, 1990; Opotow, 1990). Finally, in attribution of blame, responsibility is assigned to the victims themselves, who are described as deserving whatever befalls them (Bandura, 2002: 110). It has been shown to describe the cognition underlying unethical behavior in many contexts, including types of white-collar crime (see Douglas, 1995). 
Although others have discussed or studied similar cognitive mechanisms separately (e.g., euphemistic language, diffusion of responsibility; see Ashforth \& Anand, 2003; Diener, 1976; Kelman, 1973), Bandura conceptualized these eight moral disengagement mechanisms as a coherent set of cognitive tendencies that influence the way individuals may approach decisions with ethical import. This approach-which has characterized most of Bandura's work and represents our perspective here-argues that individuals will systematically differ in their propensities to use cognitive moral disengagement mechanisms when facing decisions with ethical import. In the set of studies reported here, we focus on the trait instantiation of moral disengagement, examining the propensity to morally disengage as a generalized cognitive orientation to the world that differentiates individuals' thinking in a way that powerfully affects unethical behavior. This stance is consistent the majority of the empirical work on moral disengagement to date, from Bandura and colleagues' (1996) study of the propensity to morally disengage in children and adolescents to a number of subsequent studies carried out by other researchers using a range of measures of the individual propensity to morally disengage (e.g., Boardley \& Kavussanu, 2007; Caprara et al., 2009; Detert et al., 2008; Duffy, Tepper, \& O'Leary-Kelly, 2002; McAlister, 2001).

\section{The Nomological Network of the Propensity to Morally Disengage}

A nomological network is a conceptual model that situates a construct of interest within the landscape of constructs that are theoretically related to it (Schwab, 1980). Though identifying and testing relationships within a nomological network is often narrowly understood as part of the process of construct validation and measurement development (Chronbach $\&$ Meehl, 1955), the work of specifying a construct's nomological network for measurement purposes also helps researchers fully understand a construct's theoretical implications. In this section, we describe the nomological network of the propensity to morally disengage and, in so doing, explain why the propensity to morally disengage is likely to be a particularly strong predictor of unethical organizational behavior relative to other constructs that share common conceptual space.

We identify three important categories of constructs within the nomological network of the propensity to morally disengage: (1) morally revelant individual personality traits, (2) moral reasoning abilities and orientations, and (3) dispositional moral emotions. For each category and construct, we explain the rationale for inclusion and the expected relationship between the nomological network factor, the propensity to moral disengage (our focal construct), and the key criterion variable (unethical 
behavior). Our intention was not to exhaustively tap every possible category or construct of potential relevance to the propensity to morally disengage but to choose theoretically salient and well-studied representative constructs within each of these three conceptual categories.

\section{Morally Relevant Individual Traits}

As noted earlier, our focus is on the dispositional propensity of individuals to morally disengage (Bandura, 1990a, 1990b). Thus, other stable dispositions that have been found to influence ethical and unethical behavior and that describe orientations toward or ways of seeing behaviors with ethical ramifications should fall within its nomological network. Three in particular have been consistently identified as important predictors of ethical and unethical behavior (Hoffman, 2000; Kish-Gephart et al., 2010): Machiavellianism (Christie \& Geis, 1970), moral identity (Aquino \& Reed, 2002), and empathy (Davis, 1983).

Machiavellianism represents an individual's propensity to be manipulative and ruthless in the pursuit of self-interested goals (Christie \& Geis, 1970). We reason that those high in Machiavellianism will be more inclined to morally disengage because such cognitive mechanisms present one means by which Machiavellians can more readily pursue their own interests without self-censure. Machiavellianism has been shown to be positively related to many transgressive behavioral tendencies, including antisocial behavior, lying, and willingness to exploit others (Christie \& Geis, 1970; Sakalaki, Richardson, \& Thépaut, 2007), as well as to a broad range of unethical decisions in a recent meta-analysis (Kish-Gephart et al., 2010). However, we believe that the propensity to morally disengage may be a particularly strong predictor of unethical organizational behavior because it captures an individual's general tendency to disengage from the self-sanctions that would otherwise prevent a wide range of unethical behaviors rather than the narrower and more specific behaviors associated with Machiavellianism.

Moral identity describes the extent to which one's self-concept incorporates the importance of being a moral person (Aquino \& Reed, 2002). Moral identity has a strong relationship with prosocial behavior and has also been linked with reduced unethical behavior (Aquino \& Reed, 2002; Shao, Aquino, \& Freeman, 2008). We expect moral identity to be negatively correlated with the propensity to morally disengage because individuals with a highly salient moral identity should be more concerned about harm to others and more likely to take responsibility for their behavior, thereby making it more unlikely that they would disengage the moral self-regulatory function (c.f., Detert et al., 2008). Further, we believe that the propensity to morally disengage will have stronger effects on behavior 
because moral identity's effect requires an activated moral self-concept (Aquino \& Reed, 2002). However, many of the mechanisms of moral disengagement disrupt the activation of the self-concept by, for example, focusing on the victim (dehumanization, attribution of blame) or by reducing personal agency (diffusion and displacement of responsibility).

Trait empathy, which includes sympathetic feelings, responsiveness to others, and an ability to cognitively understand others' perspectives, has received particular attention as an individual difference that contributes to ethical behavior and reduces unethical behavior (Eisenberg, 1986; Eisenberg \& Miller, 1987; Hoffman, 2000; Tangney, 1991). We expect trait empathy to be negatively related to the propensity to morally disengage because those predisposed to morally disengage should be less likely to take others' viewpoints or feel compassionate towards them (Detert et al., 2008). Thus, those lower in trait empathy (and thus less likely to feel compassionately towards others) will likely demonstrate higher propensities to morally disengage because the latter often also involves ignoring or distorting others' feelings, needs, or perspective. However, compared to trait empathy, morally disengaged reasoning is relevant to a much broader set of situations in work organizations. Therefore, we expect the propensity to morally disengage to have even greater general utility in the prediction of unethical organizational behavior.

\section{Moral Reasoning Abilities and Orientations}

The ethical decision-making literature has traditionally been dominated by rational/deliberative models of moral reasoning, which suggest that individuals move from awareness to deliberative judgment to motivation/intention and then to action (Rest, 1986). Constructs describing aspects of reasoning about ethical issues should relate to the propensity to morally disengage because the disengagement process is also inherently cognitive and influences, probably less consciously, the framing and making of ethically charged decisions. The three main constructs that represent different deliberative modes of ethical reasoning are cognitive moral development, idealism, and relativism.

Cognitive moral development (CMD) is considered theoretically important to the judgment phase of ethical decision making-that is, the point when an individual decides what is right or wrong in a particular situation. CMD is conceptualized in terms of a series of stages through which individuals progress as they become more cognitively advanced and autonomous in their moral reasoning (Kohlberg, 1969, 1984; Piaget, 1965). Higher levels of CMD have been found to be negatively associated with unethical choice (see Kish-Gephart et al., 2010), but the construct's potential relationship to the overall moral disengagement process or 
specific mechanisms of disengagement has never been studied. We argue that CMD is conceptually distinct from the propensity to morally disengage because the former is a measure of the level of sophistication with which one consciously reasons through ethical quandaries, whereas the propensity to morally disengage describes a dispositional tendency to use cognitive mechanisms that disengage moral self-regulatory sanctions. We propose that $\mathrm{CMD}$ will be negatively related to the propensity to morally disengage because those who engage in more complex, principled reasoning are more likely to quickly invoke moral principles (e.g., justice, the greater good) to evaluate ethical dilemmas and to decide what is right. They are also more likely to think through ethical dilemmas autonomously rather than relying on others for guidance. Therefore, they should also be less inclined to displace or diffuse responsibility onto others.

Despite its prominence in theory and research for decades, a recent meta-analysis reported that CMD is only moderately predictive of unethical choices (Kish-Gephart et al., 2010). This may be because the ability to reason deliberatively and in a sophisticated way about ethical decisions does not always lead one to behave more ethically (Rest, 1986). One possible explanation for this finding is that many unethical acts are better explained by impulsive or intuitive models (Haidt, 2001) rather than the deliberative model assumed by CMD. Although understanding of the overall process of moral disengagement is still unfolding, moral disengagement appears to often involve little conscious deliberation. Thus, we would expect not only a negative correlation between the propensity to morally disengage and CMD but also that moral disengagement is potentially "in play" in a wider variety of situations (where conscious deliberation is not involved) and therefore will show a stronger relationship with unethical behavior than CMD.

It is also important to examine the relationship between the propensity to morally disengage and the most common ethical philosophies that guide human decision making in ethical dilemma situations. Ethical philosophies describe "stated beliefs or personal preferences for particular normative frameworks" (Kish-Gephart et al., 2010: 3). Idealism and relativism describe two moral philosophies that reflect stable individual orientations toward ethical decision making. Forsyth (1980; Schlenker \& Forsyth, 1977) described idealism as an individual's belief that "the 'right' action [can] always be obtained" and relativism as the degree to which an individual "rejects universal moral rules ... when drawing conclusions about moral questions" (Forsyth, 1980: 175-176). We reason that the propensity to morally disengage will be positively correlated with relativism because holding a relativist position is facilitated by morally disengaged cognitions. Conversely, the propensity to morally disengage should be negatively correlated with idealism because idealists are driven 
to pursue absolute ethical standards and thus not be motivated to find ways (cognitively) to skirt them. In addition, similar to cognitive moral development, idealism and relativism are part of a rational/deliberative approach to ethical decision making and would only be involved in situations involving conscious deliberation. As a result, we expect the propensity to morally disengage to apply across a wider range of situations including those that do not involve conscious ethical deliberation.

\section{Dispositional Moral Emotions}

Because moral disengagement facilitates engaging in unethical behavior without feeling distress (Bandura, 1990a), moral affect/emotion constructs should also fall within the nomological network of the propensity to morally disengage. Moral emotions, including anticipatory guilt and shame, have been recognized as important motivating factors underlying ethical conduct (Haidt, 2003; Tangney, Stuewig, \& Mashek, 2007), but they have never been studied in relation to moral disengagement. The propensity to morally disengage is conceptually distinct from moral affect because the former describes a set of relatively "cool" cognitive processes stemming from parts of the brain not primarily involved in the "hot" processing included in moral affect. However, as described below, we expect that the propensity to morally disengage will be related to certain dispositional moral emotions.

Guilt has been well established as a correlate of ethical behavior (Tangney et al., 2007: 354), in part because it elicits a sense of personal responsibility for one's actions (Tangney, 1991). We expect the propensity to morally disengage to be negatively related to dispositional guilt - the tendency to experience a set of negative emotions upon judging one's own actions as harmful or immoral (Lewis, 1971; Tangney, 1991) — because guilt is activated when one's self-sanctions against unethical behavior are working correctly, and morally disengaged reasoning weakens that selfsanction trigger. Shame, however, works differently. It is a set of negative emotions about one's self rather than one's actions (Lewis, 1971; Tangney, 1991). Because the propensity to morally disengage represents a tendency to use certain types of cognitions to distance oneself from one's actions (and thus not see behavior in specific situations as being "reflective of" or "revealing of" the self), we expect the propensity to morally disengage to be unrelated to dispositional shame. As noted above, an individual's self-sanctions against unethical behavior must be working correctly in order for guilt to be activated. By contrast, the propensity to morally disengage can operate across a wide array of situations and assumes that selfsanctions may be disengaged. Therefore, we expect that the propensity 
to morally disengage will be more consistently related to unethical organizational behavior than will guilt.

\section{Hypotheses}

Thus far, we have provided theoretical rationale for expected relationships between the propensity to morally disengage and other constructs within its nomological network as well as its distinctiveness from these other constructs. However, our ultimate interest is in better understanding what explains organizationally embedded unethical behavior-behavior that is widespread enough to lead to the huge annual financial losses mentioned at the outset of this paper. Thus, we turn next to the rationale for our expectation that the propensity to morally disengage is a distinct and powerful predictor of the types of unethical behavior relevant to organizations.

The workplace provides ample opportunities for moral disengagement: Organizations tend to be hierarchical, providing opportunities for the displacement of responsibility; work is often undertaken within teams, providing opportunities for the diffusion of responsibility; organizational membership automatically defines the boundaries of an in-group, providing opportunities for moral justification (to protect the organization) and the cognitive minimization of the consequences of one's actions for those who are outside the organization (and thus in an out-group). The propensity to morally disengage might also be particularly damaging in organizational life because work contexts have been documented as triggering amoral frames of judgment (Gross, 1978). As Jackall (1988) pointed out in Moral Mazes, organizations are particularly effective at assisting individuals in bracketing off moral schemas that guide behavior elsewhere. Thus, the propensity to morally disengage is likely to be particularly relevant in the prediction of unethical behavior in organizations.

Though the link has been suggested previously (Bandura et al., 2000; Moore, 2008b), little research on the negative outcomes of moral disengagement extends directly to unethical behavior in organizations (see Duffy, Aquino, Tepper, Reed, \& O'Leary-Kelly, 2005, for an exception). Among the few empirical studies to date that have documented specific negative outcomes of the propensity to morally disengage, a couple link this propensity to organizationally relevant generic behaviors such as cheating, lying, and stealing (Detert et al., 2008). However, no study has yet shown that a carefully validated measure of the propensity to morally disengage can predict organizationally relevant unethical behavior or unethical behavior among employed adults, after controlling for a full array of other constructs likely to be related strongly to either the propensity to 
morally disengage itself or to unethical behavior. Thus, we propose and test here not merely that the propensity to morally disengage is distinct from the other types of morally salient individual differences discussed above but that this propensity will predict a variety of types of unethical behavior after controlling for these alternative explanations.

Hypothesis 1: The propensity to morally disengage will be positively related to unethical behavior after controlling for other morally salient individual traits.

Hypothesis 2: The propensity to morally disengage will be positively related to unethical behavior after controlling for deliberative moral reasoning capacity and moral philosophies.

Hypothesis 3: The propensity to morally disengage will be positively related to unethical behavior after controlling for dispositional moral emotions.

Beyond establishing that the propensity to morally disengage is a nonredundant predictor of unethical behavior, when introducing a new measure it is also important to demonstrate its value relative to existing measures of the same construct. As noted earlier, most of the few extant measures of the propensity to morally disengage are not clearly geared toward adults or designed to tap all the mechanisms of the propensity to morally disengage. The measure closest to achieving all of these aims is the one developed by Duffy and colleagues (Duffy et al., 2005; Duffy et al., 2002; McFerran et al., 2010). This measure was developed to explain undesirable and unethical behaviors at work, such as social undermining of colleagues and organizational deviance (Duffy et al., 2005; Duffy et al., 2002). Thus, we also examine how our new measure of the propensity to morally disengage compares to this existing measure, including whether the new measure still predicts unethical behavior in a workplace context after accounting for the variance explained by the alternative measure.

Hypothesis 4: The new measure of the propensity to morally disengage offered here will be positively related to unethical employee behavior after controlling for an existing measure of the propensity to morally disengage.

\section{Measure Development and Assessment}

Our development and validation of a new measure of the propensity to morally disengage was undertaken to address several specific limitations of existing measures. First, the original measure developed by Bandura and colleagues (1996) was developed specifically for use with children and 
is therefore not appropriate for adults-items, for example, include reference to schoolyard pranks and classroom teasing. Second, we also wanted to develop a measure that incorporates all of the mechanisms of moral disengagement rather than one or a few mechanisms (e.g., moral justification; see Aquino et al., 2007). Third, we wanted a measure that would be appropriate for a broad sample of adults. Other measures have been developed for a particular type of sample or context, which significantly limits their general use (e.g., Boardley \& Kavussanu, 2007; Caprara et al., 2009; Corrion et al., 2010; McAlister, 2001; Pelton et al., 2004; Rogers, 2001). Fourth, we aimed to provide the first systematic documentation of the convergent, discriminant, and predictive validity (across a wide range of samples) of a measure of the propensity to morally disengage (e.g., Detert et al., 2008; McFerran et al., 2010). The final version of the measure we introduce here is also significantly more parsimonious (only eight items) than existing measures (which range from 15 to 34 items; e.g., Bandura et al., 1996; Detert et al., 2008; Duffy et al., 2005), making it highly advantageous for use in field research.

Consistent with Bandura's theoretical claim that moral disengagement is best understood to be "multifaceted" (Bandura et al., 1996: 367), not multifactorial, and in line with both his (e.g., Bandura et al., 1996) as well as subsequent published and unpublished work on moral disengagement (Detert et al., 2008; Duffy et al., 2005; Moore, 2008a), our aim was to create a unidimensional measure of the general propensity to morally disengage. That is, while acknowledging that the eight individual mechanisms of moral disengagement represent different facets of the construct, our overarching goal was to tap these facets as part of a valid scale that assesses the general propensity to morally disengage as a higher order concept.

We began by pretesting a large pool of items (74) in a sample of 454 full-time employed adults ( $26 \%$ male, $M_{\text {age }}=36.3$ years, $S D=9.8$ years) to ensure ample representation of the construct's broad content domain and to assess the properties of various items when rated by a wide range of adults. We chose items to represent each of the mechanisms of moral disengagement, to be understandable to adults across multiple contexts and cultures, and to represent cognitions about general behaviors (such as lying, cheating, or stealing) — thus measuring a general propensity to morally disengage - rather than behaviors in specific contexts that might not be relevant to all adults (e.g., lying in a real estate negotiation). In developing these items we were guided by Bandura's theoretical descriptions of the eight moral disengagement mechanisms (Bandura, 1990a, 1990b, 1999, 2002) as well as by previous measures (Bandura et al., 1996; Detert et al., 2008; Duffy et al., 2005; Moore, 2008a).We wrote new items when we judged that existing items for a particular moral disengagement 
mechanism might not meet our criteria for developing a general scale appropriate for most adults. We used the pretest to select items with the highest factor loadings on a single factor and with the widest and least skewed distributions. The pretest left us with 47 items to further assess in Study 1.

\section{Study 1}

Study 1 was conducted to further examine the psychometric properties of the set of items developed in the pretest and to determine how parsimoniously the propensity to morally disengage could be measured while still ensuring that the multifaceted nature of the construct was represented by the scale. Prior to making decisions about scale length, it was also necessary to thoroughly examine the dimensionality of the construct - that is, to ensure that moving forward with a unidimensional measure was empirically justified. Having done this, we used statistical indices and researcher judgment to select items that created three increasingly shorter measures of the propensity to morally disengage (a 24-item, 16-item, and 8-item version). We then compared these three scales' psychometric properties and preliminary validity evidence with the goal of determining the most parsimonious way the construct could be measured without unacceptably compromising on reliability or validity standards.

\section{Methods and Measures}

Participants and procedure. One hundred and ninety four adults, who were recruited to participate through a university-based behavioral lab in the United Kingdom, completed a Web-based survey including measures of some of the variables within the construct's nomological network. The sample was diverse in age $\left(M_{\text {age }}=25.6, S D=6.7\right)$ and background (see Table 1 for demographic details). One hundred and sixteen of these participants also participated subsequently in a second study in the lab. Participants were paid $£ 5$ for completing the Web-based survey and $£ 10$ for participating in the lab study.

The propensity to morally disengage. The 47 items developed in the pretest were used to create and compare potential versions of a propensity to morally disengage measure: a 24 -item version ( 3 items per moral disengagement mechanism), a 16-item version ( 2 items per mechanism), and an 8-item version (1 item per mechanism). Appendix A lists all the items and specifies which are included in each version of the scale. Because our aim was to create a measure that represents a higher-order concept tapping each of the eight specific mechanisms of moral disengagement, we ran a factor analysis model forcing all items onto a single factor. 
TABLE 1

Overview of Samples Used in Studies 1-5, With Descriptive Statistics

\begin{tabular}{|c|c|c|c|c|c|}
\hline & \multicolumn{2}{|c|}{ Gender } & \multicolumn{2}{|c|}{ Age } & \multirow[b]{2}{*}{ Race/background } \\
\hline & Female & Male & $M$ & $S D$ & \\
\hline $\begin{array}{l}\text { Study 1: U.K.-based } \\
\text { university } \\
\text { behavioral lab } \\
\text { participants } \\
(n=194)\end{array}$ & 114 & 80 & 25.6 & 6.7 & $\begin{array}{l}\text { North America }=15, \\
\text { Europe }=98, \text { Asia } \\
=50, \text { Latin/South } \\
\text { America }=2, \\
\text { Middle East }=2, \\
\text { Africa }=21, \\
\text { other/declined to } \\
\text { answer }=6\end{array}$ \\
\hline $\begin{array}{l}\text { Study 2: } \\
\quad \text { Northeastern U.S. } \\
\text { undergraduates } \\
(n=272)\end{array}$ & 109 & 163 & 19.1 & 0.6 & $\begin{array}{l}\text { White }=228, \\
\text { African American } \\
=5, \text { Asian }=14, \\
\text { Hispanic }=5, \\
\text { foreign country } \\
\text { native }=12, \\
\text { other/declined to } \\
\text { answer }=8\end{array}$ \\
\hline $\begin{array}{l}\text { Study 3: } \\
\text { International } \\
\text { MBA students } \\
(n=304)\end{array}$ & 78 & 226 & 28.5 & 2.2 & $\begin{array}{l}\text { North America }= \\
61, \text { Europe }=107, \\
\text { Asia }=67, \\
\text { Latin/South } \\
\text { America }=39, \\
\text { Middle East }=14, \\
\text { Africa }=8, \\
\text { Australia/New } \\
\text { Zealand }=8\end{array}$ \\
\hline $\begin{array}{l}\text { Study 4: } \\
\text { Northeastern U.S. } \\
\text { undergraduates } \\
(n=250)\end{array}$ & 105 & 145 & 18.9 & 1.0 & $\begin{array}{l}\text { White }=187, \\
\text { African American } \\
=5, \text { Asian }=25, \\
\text { Hispanic }=9, \\
\text { foreign country } \\
\text { native }=18, \\
\text { other/declined to } \\
\text { answer }=6\end{array}$ \\
\hline $\begin{array}{l}\text { Study 5: Employees } \\
\text { in the southern } \\
\text { U.S. }(n=141)\end{array}$ & 69 & $67^{1}$ & 25.7 & 9.8 & $\begin{array}{l}\text { White }=87, \\
\text { Hispanic or } \\
\text { Latino/a }=26, \\
\text { African American } \\
=15, \text { Asian }=6, \\
\text { biracial }=2, \\
\text { other/declined to } \\
\text { answer }=5\end{array}$ \\
\hline
\end{tabular}

${ }^{1}$ Five respondents declined to state their gender. 
The three highest-loading items representing each moral disengagement mechanism were selected as a 24-item measure of moral disengagement $(\alpha=.90)$. This 24 -item measure was then trimmed to 16 items by dropping one item for each moral disengagement mechanism $(\alpha=.88)$. Items were dropped based on a combination of statistical (e.g., factor loadings) and theoretical (e.g., ensuring each tactic was most clearly represented by the items) considerations. Finally, the scale was trimmed to eight items ( $\alpha=$ .80 ), with each moral disengagement mechanism represented by a single item. The choice of which items to drop was in this case based primarily on theoretical grounds, attempting to keep a highly representative item for each mechanism while ensuring that the measure still had broad content coverage and acceptable estimated reliability.

Convergent and discriminant validity measures. Machiavellianism was measured using the standard 20-item Mach IV (Christie, 1970), which asks respondents to rate their level of agreement with a series of statements (on a 5-point continuum from strongly disagree to strongly agree). A sample item is, "It is hard to get ahead without cutting corners here and there." Estimated reliability of the measure in this sample $(\alpha$ $=.65$ ) was low (though low reliabilities in the Mach IV are typical, see Ray, 1983; Wrightsman, 1991).The measure of moral identity (Aquino \& Reed, 2002) presents a set of characteristics of "moral" people (e.g., caring, compassionate, fair) as stimuli and then asks respondents (using a 7-point continuum from strongly disagree to strongly agree) to assess how important it is to be viewed as an individual who shares those characteristics. We used the five items ( $\alpha=.87)$ that assess "internalization" of a moral identity because this component measures the strength of individuals' self-concept as moral people. A sample item (rated after seeing the list of "moral characteristics") is, "I strongly desire to have these characteristics." We assessed empathy using two components of Davis' (1983) Interpersonal Reactivity Index (IRI): a seven-item measure of perspective taking (PT), or the ability to adopt others' viewpoints, and a seven-item measure of empathetic concern, or the tendency to feel compassion towards others. Respondents reported the degree to which they feel the items are true about themselves, from $1=$ not at all true to $7=$ very true. $\mathrm{A}$ sample item in the perspective-taking subscale $(\alpha=.75)$ is, "I try to look at everybody's side of a disagreement when I make a decision," and in the EC subscale $(\alpha=.78)$ is, "I am often quite touched by things that I see happen."

Because social desirability can affect reporting in studies of ethicsrelated beliefs and behaviors, we wanted to ensure that our new measure of the propensity to morally disengage was not highly correlated with a measure of social desirability bias. Thus all participants completed a 10-item version of the traditional 33-item Marlowe-Crowne measure 
TABLE 2

Summary of Fit Indices for all CFA Models, Study 1

\begin{tabular}{lccccccc}
\hline \hline & $\chi^{2}$ & $d f$ & $\chi^{2} / d f$ & RMSEA & SRMR & NNFI & CFI \\
\hline $\mathbf{2 4}$ item measures & & & & & & & \\
24 items on 1 factor & 588 & 252 & 2.54 & .090 & .080 & .90 & .91 \\
24 items on 8 factors & 507 & 224 & 2.26 & .089 & .078 & .90 & .91 \\
$\quad$ 24 items on 8 factors on 1 second-order & 560 & 244 & 2.30 & .092 & .081 & .91 & .92 \\
$\mathbf{1 6}$ item measures & & & & & & & \\
$\quad$ 16 items on 1 factor & 254 & 104 & 2.44 & .099 & .075 & .91 & .93 \\
16 items on 8 factors & 193 & 76 & 2.54 & .098 & .070 & .91 & .94 \\
$\quad$ 16 items on 8 factors on 1 second-order & 244 & 96 & 2.54 & .100 & .074 & .91 & .93 \\
$\mathbf{8}$ item measure & & & & & & & \\
$\quad 8$ items on 1 factor & 27 & 20 & 1.35 & .045 & .043 & .98 & .99 \\
\hline
\end{tabular}

of social desirability (Crowne \& Marlowe, 1960; Strahan \& Gerbasi, 1972). For this measure, participants responded to a series of yes/no questions about negative behaviors or cognitions that are thought to be universal but socially embarrassing or unattractive (e.g., "I never resent being asked to return a favor") and therefore potentially elicit socially desirable responses. The number of times that a participant answers "no" is summed as a measure of his/her social desirability response bias.

\section{Results}

Prior to comparing results for three single-factor measures of differing length, we first thoroughly explored the dimensionality of these three measures of the propensity to morally disengage in a multistep process. We began by estimating a series of confirmatory factor analysis models using LISREL 8.8 (Jöreskog \& Sörbom, 2009) for the two longer versions of the scale: one that forced all the items to load onto a single latent variable (a 1-factor model), one that forced the items to load onto eight different factors representing each of the moral disengagement mechanisms (an 8-factor model), and one model where eight first-order factors (comprised by forcing the items tapping each moral disengagement mechanism onto separate factors) were forced to load onto a second-order latent variable (the second-order factor model). The resultant fit indices for each of these models are presented in Table 2. The first thing the table makes clear is that all of the models fit the data adequately, with RMSEA values less than .10, SRMR values less than .08, and CFI and NNFI indices all greater than .90. In particular, the fit indices for a single-factor model run using the 8-item version of the scale indicate a good fit of the data to the model $\left(\chi^{2}=26, d f=20, n s, \mathrm{NNFI}=.98, \mathrm{CFI}=.99, \mathrm{SRMR}=.04\right.$, 
RMSEA $=.05)$ according to current standards-values of less than .05 for the RMSEA (Browne \& Cudeck, 1993; Hu \& Bentler, 1999) and CFI and NNFI values greater than .95 (Hu \& Bentler, 1999).

The second thing evident from the factor analyses results summarized in Table 2 is that statistical criteria alone do not provide strong evidence in this case for preferring one factor structure over another. For the 16and 24-item versions of the scale, the CFA models that fit the data to eight separate factors have very slightly better fit indices (only models with the same observed variables are directly comparable). This is an expected result given the two or three items assessing each specific mechanism are intended to be more interrelated with each other than with those items assessing the other mechanisms. Conversely, the fit indices for the models that represent the best match to Bandura's theoretical expectation that moral disengagement should be conceived of as "multifaceted" (Bandura et al., 1996: 367) — that is, as a higher-order construct that encompasses eight different mechanisms in a unified way-are slightly lower than the other models run with the same number of items. This slight decrement in fit (compared to models involving only a first-order factor) is expected mathematically (Marsh, 1987) and thus does not necessarily have practical import. The simplest latent variable models for the 16- and 24-item versions of the scale-those that load all items onto a single first-order latent factor-have fit indices in between those for the 8-factor and secondorder factor models. However, differences in fit on the various indices are of an average magnitude of just .01, a size considered to indicate measurement invariance between comparable models (Cheung \& Rensvold, 2002). With this much similarity in fit among the comparable models, along with Bandura's theorization, the rule of parsimony suggests selecting a single-factor structure for this new measure of the propensity to morally disengage (Kline, 1988).

To further assess the appropriateness of proceeding with a single-factor solution (i.e., a unidimensional approach), we then examined whether measuring the propensity to morally disengage in various multidimensional and unidimensional ways resulted in any substantive empirical differences. Specifically, we created several measures of the propensity to morally disengage that were either (a) latent variable measures derived from the factor loadings from the various first-order or second-order CFA models or (b) simple average measures derived by taking the average of the items forming the scale. The latent variable approach allows for differential weighing of each item and of each moral disengagement mechanism (in the second-order model), whereas the simple average approach (where each item is assigned equal weight) assumes a unifactorial structure of the data with all items representing the single underlying factor equally well. The three versions of the 24-item measure-one an average of the 
scale items and the other two latent variable measures derived from the factor loadings for a single factor model, and the hierarchical secondorder factor model, respectively - are all correlated with each other at $r=$ .98 or higher. ${ }^{1}$ The three parallel versions (simple average and first- and second-order latent variables) created using 16 items and the two parallel versions (simple average and first-order latent variable) created using eight items likewise have bivariate correlations all approaching 1.0. These results also suggest that there is no practical difference, at any of the three scale lengths, between the simplest item-average unidimensional measures and those that take into account differences in the weights assigned to particular moral disengagement items or mechanisms in the formation of latent variables.

Having concluded on statistical and practical grounds that measuring the propensity to morally disengage in more complex ways produces no meaningful advantage, we proceeded in a third step to compare different length (24-, 16- and 8-item) versions of the propensity to morally disengage scale constructed as simple averages of the items. As shown in Table 3, the intercorrelations among the three different-length versions of the scale are all above .90 . Moreover, the correlations of the three different-length versions of the propensity to morally disengage scales with the other constructs assessed in Study 1 are strongly consistent with theory and predictions. For example, the 8 -item propensity to morally disengage measure correlates positively with Machiavellianism $(r=.44$, $p<.01)$ and negatively with moral identity $(r=-.55, p<.01)$ and two facets of empathy: perspective taking $(r=-.40, p<.01)$ and empathetic concern $(r=-.46, p<.01)$. This measure is also uncorrelated with social desirability $(r=.05, n s)$. All of these relationships are in the expected direction, and none is so strong as to suggest that the propensity to morally disengage is redundant with any of the other constructs. Importantly, the correlations between the 8-, 16- and 24-item versions of the propensity to morally disengage measure and all of the nomological network variables assessed in Study 1 are substantively equivalent - that is, all are in the hypothesized directions and of similar magnitude. Thus, we determined that we could meet our objective of creating a more parsimonious measure of the propensity to morally disengage than has previously been offered

\footnotetext{
${ }^{1}$ We did not include in these comparisons (for the 24- and 16-item scale versions) eight first-order latent variables representing each moral disengagement mechanism separately for two reasons: (1) the second-order latent variable is essentially doing this in the creation of the eight first-order latent variables subsequently loaded onto the second-order latent variable, and this approach better represents the theory of the propensity to morally disengage as a single higher order construct with subdimensions; (2) reliabilities for the twoand three-item scales representing each moral disengagement mechanism that result from this approach are systematically far below the conventional cutoff of .70.
} 
TABLE 3

Means, Standard Deviations, Correlations Among Study 1 Variables

\begin{tabular}{|c|c|c|c|c|c|c|c|c|c|}
\hline Variable & $M$ & $S D$ & 1 & 2 & 3 & 4 & 5 & 6 & 7 \\
\hline $\begin{array}{l}\text { 1. Propensity to } \\
\text { morally disengage } \\
(8 \text {-items })^{\mathrm{a}}\end{array}$ & 2.57 & .99 & $(.80)$ & & & & & & \\
\hline $\begin{array}{l}\text { 2. Propensity to } \\
\text { morally disengage } \\
(16-i t e m s)^{\mathrm{a}}\end{array}$ & 2.88 & .92 & $.93^{* *}$ & $(.88)$ & & & & & \\
\hline $\begin{array}{l}\text { 3. Propensity to } \\
\text { morally disengage } \\
(24-i t e m s)^{\mathrm{a}}\end{array}$ & 2.99 & .88 & $.90^{* *}$ & $.98^{* *}$ & $(.90)$ & & & & \\
\hline 4. Machiavellianism ${ }^{\mathrm{a}}$ & 2.83 & .42 & $.44^{* *}$ & $.52^{* *}$ & $.54^{* *}$ & $(.65)$ & & & \\
\hline 5. Moral identity ${ }^{\mathrm{a}}$ & 6.13 & 1.01 & $-.55^{* *}$ & $-.54^{* *}$ & $-.54^{* *}$ & $-.34^{* *}$ & $(.87)$ & & \\
\hline $\begin{array}{l}\text { 6. Perspective } \\
\text { taking }^{\mathrm{a}}\end{array}$ & 4.80 & .91 & $-.40^{* *}$ & $-.36^{* *}$ & $-.38^{* *}$ & $-.29^{* *}$ & $.38^{* *}$ & $(.75)$ & \\
\hline 7. $\mathrm{EC}^{\mathrm{a}}$ & 5.22 & .91 & $-.46^{* *}$ & $-.46^{* *}$ & $-.47^{* *}$ & $-.31^{* *}$ & $.56^{* *}$ & $.38^{* *}$ & $(.78)$ \\
\hline $\begin{array}{l}\text { 8. Social } \\
\text { desirability }^{\mathrm{a}}\end{array}$ & 3.65 & 1.54 & .05 & .00 & -.01 & .04 & $-.15^{*}$ & $-.16^{*}$ & .00 \\
\hline
\end{tabular}

${ }^{\mathrm{a}} N=194,{ }^{\mathrm{b}} N=116 .{ }^{* *} p<.01,{ }^{*} p<.05$. Where appropriate, alpha reliabilities appear along the diagonal.

in the literature by proceeding with the 8 -item version of the scale (which has estimated reliability of .80 in Study 1).

To statistically confirm that our new 8 -item measure of the propensity to morally disengage is not redundant with related constructs, we followed recommendations by Schwab (1980) and DeVellis (1991) in considering results from several confirmatory factor analysis models estimated using the eight items from the propensity to morally disengage measure as well as all items assessing the other nomological network constructs included in Study 1-namely, Machiavellianism, moral identity, perspective taking, and empathetic concern. We compared fit indices for the hypothesized model - that is, a five-factor model where we forced all the items to load onto factors representing their theorized construct — with those for several 4-factor models where we forced the propensity to morally disengage items to load on the same factor as the items from one of the related constructs (i.e., a 4-factor model forcing the moral disengagement items to load with the items for Machiavellianism, a 4-factor model forcing the moral disengagement items to load with the moral identity items, etc.). If any of the 4-factor models fit the data significantly better than the 5factor model, it would indicate that our new measure may be redundant with another measure. Instead, chi-square difference tests indicate that the data fit the hypothesized five-factor model (with the items measuring 
the propensity to morally disengage restricted to their own latent factor; $\left.\chi^{2}=1551, d f=979\right)$ significantly better $(p<.001$ for all comparisons) than any of the models where the moral disengagement items were forced to load with Machiavellianism $\left(\chi^{2}=1800, d f=983\right)$, moral identity $\left(\chi^{2}=1723, d f=983\right)$, perspective taking $\left(\chi^{2}=1699, d f=983\right)$, or empathetic concern $\left(\chi^{2}=1650, d f=983\right)$. These results provide further evidence that the new propensity to morally disengage scale is empirically distinct from related constructs.

We therefore concluded from Study 1 that the propensity to morally disengage can be appropriately assessed with the new 8-item unidimensional scale. Appendix A presents these eight items (in bold), as well as the other sixteen items used to form the 16- and 24-item versions also considered in Study 1. In Studies 2-5, we continued the assessment of the 8-item version's psychometric properties, with particular focus on its distinctness from and incremental validity beyond additional constructs in its nomological network. Specifically, we used four separate samples to test whether the new 8-item version of the propensity to morally disengage scale predicts multiple types of unethical decisions after controlling for sets of measures of constructs from each of the three nomological network categories previously discussed, as well as a longer extant measure of the propensity to morally disengage.

Incremental Predictive Validity Studies

Study 2

Study 2 tested Hypothesis 1 -that the propensity to morally disengage will have incremental validity in the prediction of unethical decision making, after controlling for four morally relevant individual trait differences (Machiavellianism, moral identity, and two facets of empathy) and socially desirable response tendencies. The dependent variable was a self-report measure of several types of unethical behavior (cheating, lying, and stealing).

\section{Methods and Measures}

Participants and procedure. For extra credit, 272 students at a university in the Northeastern U.S. completed one survey (with the propensity to morally disengage and other independent variable measures) midway through an undergraduate business course (not an ethics course); 242 of these students completed a second survey (including the unethical behavior measure) 1 month later. Demographic data are presented in Table 1. 
The propensity to morally misengage. At Time 1, participants completed the 8-item propensity to morally disengage scale $(\alpha=.76$ in this sample). Fit indices from a CFA indicate a good fit of the data to a 1-factor model (e.g., $\mathrm{CFI}=1.0, \mathrm{NNFI}=1.0, \mathrm{RMSEA}=0$, $\mathrm{SRMR}=.03$ ).

Control variables. As in Study 1, Machiavellianism was measured using the 20-item Mach IV (Christie, 1970, $\alpha=.69$ in this sample), moral identity was measured using Aquino and Reed's (2002) 5-item internalization measure ( $\alpha=.84$ in this sample), and perspective taking and empathetic concern were measured using the two seven-item subscales from Davis' (1983) IRI ( $\alpha \mathrm{s}=.75$ and .78, respectively, in this sample). All participants also completed the same 10-item measure of social desirability as in Study 1 (Strahan \& Gerbasi, 1972).

Dependent variable. We first sought to test whether the new propensity to morally disengage measure would show incremental validity in the prediction of a broad range of unethical behavior, and thus used Detert and colleagues' (2008) measure of cheating, lying, and stealing. This measure, obtained 1 month after the initial survey, asks respondents to indicate how often they have engaged in 13 unethical behaviors (e.g., "Taking low-cost items from a retail store") using a 5-point scale ranging from never to many times $(\alpha=.82)$.

\section{Results}

Means, standard deviations, alpha reliabilities (where appropriate), and bivariate correlations for the Study 2 variables are reported in Table 4. The correlations between the propensity to morally disengage scale and other measures are consistent with expectations and with the results from Study 1 . In this sample as well, the propensity to morally disengage correlates positively with Machiavellianism $(r=.46, p<.01)$ and negatively with moral identity $(r=-.42, p<.01)$ and two facets of empathy: perspective taking $(r=-.33, p<.01)$ and empathetic concern $(r=-.48, p$ $<.01)$. Again, none of these relationships are so strong as to indicate that the propensity to morally disengage is redundant with any of the other constructs. We further confirmed this by estimating and comparing the results of five CFA models: one where the propensity to morally disengage items and those tapping the other four nomological network variables are all represented by their own latent factors $\left(\chi^{2}=1950, d f=1024\right)$, and four that force the propensity to morally disengage items to load with Machiavellianism $\left(\chi^{2}=2010, d f=1029\right)$, moral identity $\left(\chi^{2}=2233\right.$, $d f=1029)$, perspective taking $\left(\chi^{2}=2290, d f=1029\right)$, or empathetic concern $\left(\chi^{2}=2152, d f=1029\right)$, respectively. Chi-square difference tests 
TABLE 4

Means, Standard Deviations, Correlations Among Study 2 Variables

\begin{tabular}{|c|c|c|c|c|c|c|c|c|c|}
\hline Variable & $M$ & $S D$ & 1 & 2 & 3 & 4 & 5 & 6 & 7 \\
\hline $\begin{array}{l}\text { 1. Propensity to } \\
\text { morally } \\
\text { disengage }^{\mathrm{a}}\end{array}$ & 2.79 & .87 & $(.76)$ & & & & & & \\
\hline 2. Machiavellianism & 2.77 & .41 & $.46^{* *}$ & (.69) & & & & & \\
\hline 3. Moral identity ${ }^{\mathrm{a}}$ & 6.29 & .92 & $-.42^{* *}$ & $-.44^{* *}$ & $(.84)$ & & & & \\
\hline $\begin{array}{l}\text { 4. Perspective } \\
\text { taking }^{\mathrm{a}}\end{array}$ & 4.49 & .98 & $-.33^{* *}$ & $-.21^{* *}$ & $.25^{* *}$ & $(.81)$ & & & \\
\hline $\begin{array}{l}\text { 5. Empathetic } \\
\text { concern }^{\mathrm{a}}\end{array}$ & 5.02 & .94 & $-.48^{* *}$ & $-.43^{* *}$ & $.55^{* *}$ & $.35^{* *}$ & $(.79)$ & & \\
\hline $\begin{array}{l}\text { 6. Social } \\
\text { desirability }^{\mathrm{a}}\end{array}$ & 3.61 & 1.33 & $-.16^{* *}$ & .07 & -.04 & -.07 & -.07 & & \\
\hline $\begin{array}{l}\text { 7. Self-reported } \\
\text { cheating, lying, } \\
\text { and stealing }{ }^{\mathrm{b}}\end{array}$ & 1.83 & .50 & $.31^{* *}$ & $.20^{* *}$ & $-.21^{* *}$ & $-.18^{* *}$ & $-.16^{*}$ & -.08 & $(.82)$ \\
\hline
\end{tabular}

${ }^{\mathrm{a}} N=272$ at Time $1,{ }^{\mathrm{b}} N=245$ at Time $2 .{ }^{* *} p<.01,{ }^{*} p<.05$. Where appropriate, alpha reliabilities appear along the diagonal.

confirm that, in every case, the data fit the model with a separate factor for the propensity to morally disengage significantly better $(p<.001$ for all comparisons), providing further evidence that the propensity to morally disengage is empirically distinct from related constructs.

The positive and significant bivariate relationship $(r=.31, p<.01)$ with self-reported cheating, lying, and stealing behavior provides initial evidence of criterion validity for the new propensity to morally disengage scale. In fact, the propensity to morally disengage has the strongest bivariate relationship (among the Study 2 variables) with this measure of unethical behavior. To test Hypothesis 1, we examined the additional variance accounted for by the propensity to morally disengage in the prediction of self-reported cheating, lying, and stealing, beyond that explained by four other morally relevant individual differences and social desirability. In the first step of a linear regression (see the first and second columns of Table 5), we entered the measures of Machiavellianism, moral identity, perspective taking, empathetic concern, and social desirability. In the second step, we added the propensity to morally disengage measure. In neither step are any of the control variables individually predictive of self-reported cheating, lying, and stealing. However, in support of Hypothesis 1, the propensity to morally disengage significantly predicts self-reported unethical behaviors $(\beta=.22, p<.01)$. Adding this variable to the equation increases $R^{2}$ by $3 \%(\Delta F[1,236]=7.96, p<.01)$. 
PERSONNEL PSYCHOLOGY

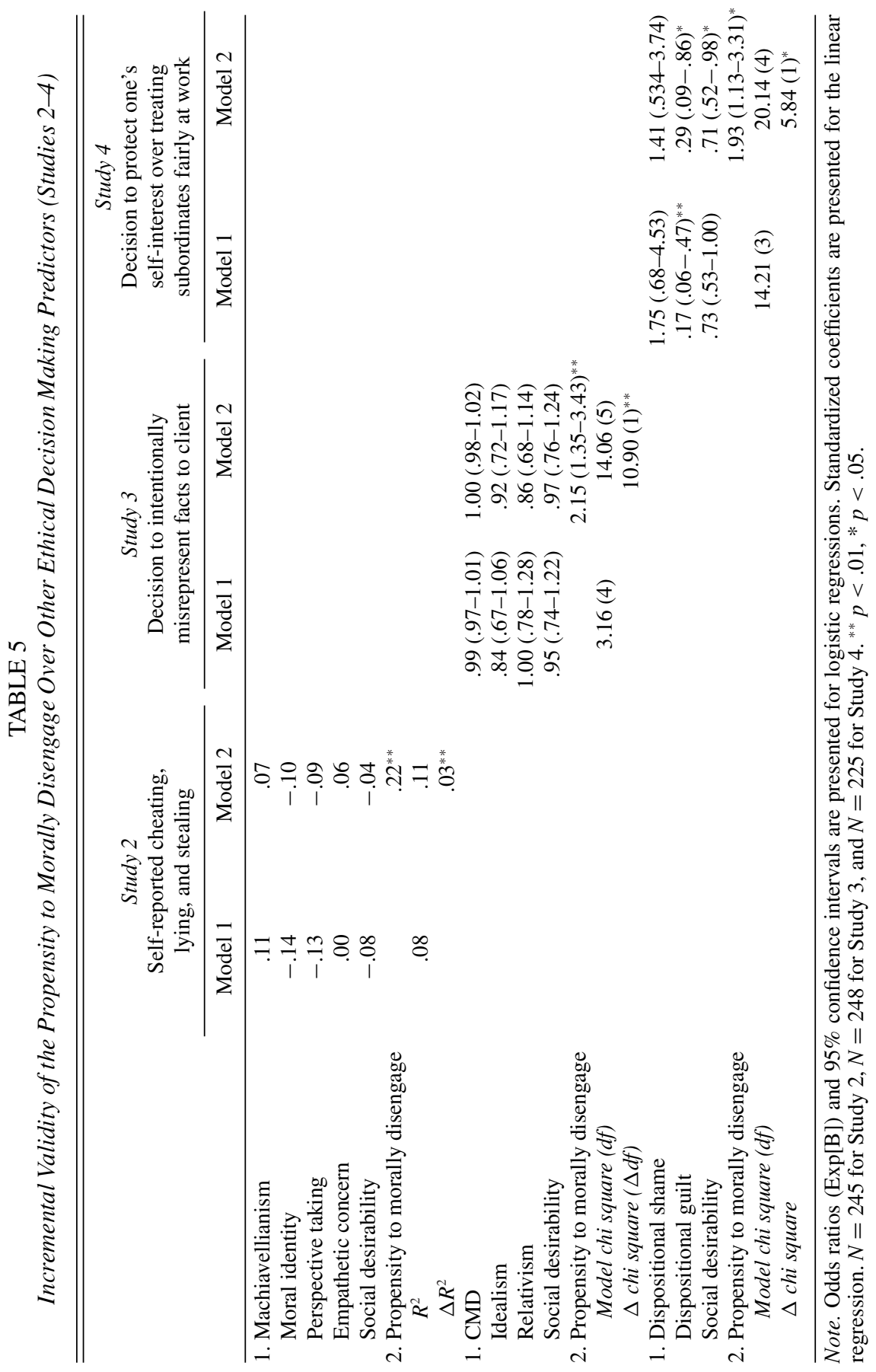




\section{Study 3}

Study 3 tested Hypothesis 2-that the propensity to morally disengage will show incremental validity in the prediction of unethical behavior after controlling for three deliberative moral reasoning or ethical philosophy factors (cognitive moral development, idealism and relativism) and socially desirable response tendencies.

\section{Methods and Measures}

Participants and procedure. Three hundred and four students (74\% male, $M_{\text {age }}=28.5$ years, $S D=2.2$ years $)$ in an international MBA program participated in the study. Participants had an average of 5.6 years of work experience prior to entering the program $(S D=1.9)$ (see Table 1 for additional demographics). Respondents completed a survey with the 8item propensity to morally disengage scale and other measures as part of their course participation in a class on ethics and corporate social responsibility. To minimize contamination of results due to the class' subject matter, they completed the survey before the class began. The measure of unethical behavior (the dependent variable) was collected as the class began (Time 2), as part of the first assignment.

The propensity to morally disengage. We used the same 8-item propensity to morally disengage scale developed in Study 1 ( $\alpha=.70$ in this sample). The fit indices from a confirmatory factor analysis again revealed a good fit of the data to a 1 -factor model $(\mathrm{CFI}=.99, \mathrm{NNFI}=$ $.99, \mathrm{RMSEA}=.02, \mathrm{SRMR}=.04)$.

Control variables. Cognitive moral development was measured using the Defining Issues Test (DIT; Rest, 1986, 1990). The original test presents respondents with six moral dilemmas, asking them to rank the four most important considerations they would use in making a decision about what to do in each dilemma. A score, which is computed from those considerations ranked highest, is considered a measure of the proportion of one's reasoning that is at the highest (principled) level of moral reasoning. We used a short form version of the DIT that uses three of the six scenarios; this version has been shown to correlate above .90 with scores on the longer version (Rest, 1990).

Idealism and relativism were measured using Forsyth's Ethics Position Questionnaire (1980), which measures an individual's level of agreement with general statements on a 9-point continuum, ranging from completely disagree to completely agree. Ten items measured idealism $(\alpha=.85$, sample item: "It is never necessary to sacrifice the welfare of others") and ten items measured relativism $(\alpha=.80$, sample item: "What is ethical 
TABLE 6

Means, Standard Deviations, Correlations Among Study 3 Variables

\begin{tabular}{|c|c|c|c|c|c|c|c|}
\hline Variable & $M$ & $S D$ & 1 & 2 & 3 & 4 & 5 \\
\hline 1. Propensity to morally disengage ${ }^{a}$ & 2.12 & .77 & $(.70)$ & & & & \\
\hline 2. Cognitive moral development ${ }^{\mathrm{a}}$ & 40.44 & 16.88 & $-.23^{* *}$ & & & & \\
\hline 3. Idealism ${ }^{\mathrm{a}}$ & 5.84 & 1.40 & $-.27^{* *}$ & .01 & $(.85)$ & & \\
\hline 4. Relativism ${ }^{\mathrm{a}}$ & 4.82 & 1.31 & $.29^{* *}$ & -.10 & $-.18^{* *}$ & $(.80)$ & \\
\hline 5. Social desirability ${ }^{\mathrm{a}}$ & 3.49 & 1.34 & -.05 & -.03 & .03 & -.03 & \\
\hline $\begin{array}{l}\text { 6. Unethical decision (dummy } \\
\text { variable coded } 1 \text { if decided } \\
\text { to send fraudulent fax) }\end{array}$ & .18 & & $.23^{* *}$ & -.07 & -.10 & .01 & .05 \\
\hline
\end{tabular}

${ }^{\mathrm{a}} N=304$ at Time $1,{ }^{\mathrm{b}} N=258$ at Time $2 .{ }^{* *} p<.01,{ }^{*} p<.05$. Where appropriate, alpha reliabilities appear along the diagonal.

varies from one situation and society to another"). All participants also completed the same social desirability measure used in Studies 1 and 2.

Dependent variable. The unethical outcome used in this study was developed by coding MBA students' responses to an ethically charged case assignment ("Conflict on a Trading Floor," Badaracco \& Useem, 2006) that asks participants to put themselves in the position of a junior trader at a large bank whose supervisor is requesting them to send a fax containing misleading and, in fact, fraudulent information to a client. Students were asked (prior to the beginning of the class) to write one page explaining what they would do if they were in the same situation and why. Responses ranged from sending the fax, to voicing concerns to others, to refusing to send the fax. These decisions about the case were coded by a trained independent coder. An unethical decision was represented by a dummy variable coded " 1 " if an individual explicitly stated that s/he would send the fax (18\% of the sample stated this).

\section{Results}

Means, standard deviations, alpha reliabilities (where appropriate), and correlations among the Study 3 variables are reported in Table 6 . As expected, the propensity to morally disengage is modestly negatively correlated with cognitive moral development $(r=-.23, p<.01)$ and idealism $(r=-.27, p=<.01)$ and positively correlated with relativism $(r=.29, p<.01)$. Again, a CFA model where the moral propensity to morally disengage items are forced onto their own latent factor $\left(\chi^{2}=\right.$ $827, d f=347$ ) fit significantly better (both chi-square difference tests significant at $p<.001$ ) than models forcing the propensity to morally disengage items to load on the same factor with the idealism items 
$\left(\chi^{2}=2010, d f=1029\right)$ or the relativism items $\left(\chi^{2}=2233, d f=1029\right)$. The computation of cognitive moral development makes it impossible to include it in CFA models. But, as the least strongly correlated with the propensity to morally disengage of the three nomological network variables included in this study (see Table 6), it is reasonable to conclude from the other results that these two constructs are also distinct.

As predicted, the propensity to morally disengage is positively correlated with the subsequently measured unethical decision to send the fax $(r=.23, p<.01)$. In fact, the propensity to morally disengage is the only variable in this study that is significantly related to the dependent variable. To test Hypothesis 2, we examined the variance accounted for, beyond that explained by three moral reasoning and ethical philosophy factors and social desirability, by the propensity to morally disengage in the prediction of a work-related unethical decision. We used logistic regression to examine the difference between the chi-square statistics for the more and less restricted models (i.e., models that do and do not include the propensity to morally disengage). In the first step of the regression (see Column 3 of Table 5), the decision to send the fax was regressed onto the measures of cognitive moral development, idealism, relativism, and social desirability. In the second step (Column 4, Table 5), the propensity to morally disengage measure was added to the equation. The difference in the chi-square statistic between the first and second models is significant $\left(\Delta \chi^{2}=10.90\right.$ [1 d.f.], $\left.p<.01\right)$. Adding the variable for the propensity to morally disengage $(\operatorname{Exp}[\mathrm{B}]=2.15, p<.01)$ in the second step contributes significantly to the prediction of whether an individual is likely to make the unethical decision. An odds ratio of 2.15 for moral the propensity to morally disengage means that, holding cognitive moral development, idealism, relativism, and social desirability constant, for every one unit (on the 1-7 scale) increase in an individual's measured level of the propensity to morally disengage, he or she is $115 \%$ more likely to send the fraudulent fax. This result provides support for Hypothesis 2. Specifically, these results provide evidence that the propensity to morally disengage predicts an unethical decision beyond three important independent variables that represent the traditional rational/deliberative approach to ethical decision making.

\section{Study 4}

Study 4 tested Hypothesis 3 - that the propensity to morally disengage will have incremental validity in the prediction of unethical behavior, measured here as a self-serving decision in a work context, after controlling for two measures of moral affect (dispositional shame and guilt) and socially desirable response tendencies. 


\section{Methods and Measures}

Participants and procedure. For extra credit, 250 undergraduate students at a university in the Northeastern U.S. completed one survey (with the propensity to morally disengage and social desirability measures) midway through a business course (Time 1), and 225 of these students completed a second survey (containing the other measures, including the dependent variable) 1 month later (Time 2). Demographic data are presented in Table 1.

The propensity to morally disengage. All participants completed the 8 -item propensity to morally disengage measure at Time 1 ( $\alpha=.77$ in this sample). Fit indices from a confirmatory factor analysis again revealed a good fit of the data to a one-factor model $(\mathrm{CFI}=.99$, NNFI $=.98$, RMSEA $=.04$, SRMR $=.04)$.

Control variables. Dispositional shame and guilt were measured using the Test of Self-Conscious Affect (TOSCA; Tangney, Wagner, \& Gramzow, 1989). The scale is comprised of 16 brief scenarios (for example, "You are driving down the road, and you hit a small animal"); after each scenario there are two statements, one tapping guilt (in this example, "You would feel bad if you hadn't been more alert driving down the road") and the other tapping shame (in this example, "You would think: 'I'm terrible."'). The mean of each set of eight statements (assessed on a 5-point scale ranging from not very likely to very likely) is considered a measure of respondents' dispositional guilt $(\alpha=.77)$ and shame $(\alpha=$ .70 ), respectively. To control for socially desirable responding, all participants also completed the same 10-item measure of social desirability used in Studies 1-3.

Dependent variable. The unethical outcome in this study was operationalized using responses to an exercise that allowed respondents to make a work-related self-serving decision. Participants read a one-page description of a managerial dilemma in which they are asked to play the role of a manager who discovers that a subordinate-though they do not know which one-has made an error that will cost the company $\$ 90,000$. The manager's own supervisor then demands that he or she either personally take the blame (resulting in a loss of $50 \%$ of his/her own bonus) or blame a member of his or her team (costing the team member $50 \%$ of his or her bonus). The choice was coded as a self-serving decision if the respondent chose the latter option (11\% made this choice) because the manager in the exercise cannot fairly blame any specific team member; doing so saves the manager's (i.e., the respondent's) bonus at the expense of his or her subordinate. 
TABLE 7

Means, Standard Deviations, Correlations Among Study 4 Variables

\begin{tabular}{|c|c|c|c|c|c|c|}
\hline Variable & $M$ & $S D$ & 1 & 2 & 3 & 4 \\
\hline $\begin{array}{l}\text { 1. Propensity to morally } \\
\text { disengage }^{\mathrm{a}}\end{array}$ & 2.74 & .86 & $(.77)$ & & & \\
\hline 2. Dispositional shame ${ }^{a}$ & 3.01 & .51 & .01 & $(.70)$ & & \\
\hline 3. Dispositional guilt $\mathrm{t}^{\mathrm{a}}$ & 3.98 & .46 & $-.47^{* *}$ & $.31^{* *}$ & $(.77)$ & \\
\hline 4. Social desirability ${ }^{\mathrm{a}}$ & 3.69 & 1.34 & .08 & -.02 & $-.14^{*}$ & \\
\hline $\begin{array}{l}\text { 5. Self-interested } \\
\text { decision (dummy } \\
\text { variable coded } 1)^{\mathrm{b}}\end{array}$ & .11 & & $.23^{* *}$ & .00 & $-.20^{* *}$ & -.09 \\
\hline
\end{tabular}

${ }^{\mathrm{a}} N=250$ at Time $1,{ }^{\mathrm{b}} N=225$ at Time $2 .{ }^{* *} p<.01,{ }^{*} p<.05$. Where appropriate, alpha reliabilities appear along the diagonal.

Results

Means, standard deviations, alpha reliabilities (where appropriate), and correlations among the Study 4 variables are reported in Table 7. Bivariate relationships are consistent with expectations. The propensity to morally disengage correlates negatively with dispositional guilt ( $r=$ $-.47, p<.01)$ and is uncorrelated with dispositional shame $(r=.01$, $n s)$. As in Studies 2 and 3, CFA models forcing the propensity to morally disengage items to load onto their own latent factor $\left(\chi^{2}=1641, d f=737\right)$ result in significantly better fit indices (both chi-square difference tests are significant at $p<.001$ ) than models forcing the propensity to morally disengage items to load onto factors measuring shame $\left(\chi^{2}=1797, d f=\right.$ $739)$ or guilt $\left(\chi^{2}=1761, d f=739\right)$.

The positive relationship between the propensity to morally disengage and the self-serving decision at work $(r=.23, p<.01)$ provides further evidence of criterion validity for the new propensity to morally disengage scale. Again, the propensity to morally disengage has the strongest bivariate relationship (among the independent variables) with the outcome measure. To test Hypothesis 3, we examined the additional variance accounted for, beyond that explained by the measures of moral affect and social desirability, by the propensity to morally disengage in the prediction of the self-interested work decision. We used logistic regression to examine the difference between the chi-square statistics for a more and less restricted model (i.e., models that do and do not include the propensity to morally disengage). In the first step of the regression (see the Column 5 of Table 5), the self-serving decision was regressed onto dispositional shame, guilt, and social desirability. In the second step (Column 6 of 
Table 5), the measure of the propensity to morally disengage was added to the equation. The difference in the chi-square statistic between the first and second models $\left(\Delta \chi^{2}=5.84\right.$ [1 d.f.], $\left.p<.05\right)$ is significant. Adding the propensity to morally disengage measure $(\operatorname{Exp}[\mathrm{B}]=1.93, p<.05)$ in the second step adds significantly to the prediction of the self-serving decision. An odds ratio of 1.93 for the propensity to morally disengage means that, holding shame, guilt, and social desirability constant, for each one unit increase in an individual's measured level of the propensity to morally disengage, he or she is $93 \%$ more likely to make a self-interested decision at the expense of a subordinate. This result provides support for Hypothesis 3.

\section{Study 5}

Study 5 tested Hypothesis 4 - that the propensity to morally disengage will have incremental validity in the prediction of unethical behavior, measured here as the unethical work behaviors of current employees as rated by both their peers and supervisors, after controlling for the most relevant extant measure of the propensity to morally disengage.

\section{Methods and Measures}

Participants and procedure. A total of 399 individuals-141 employees matched with 129 supervisors and 129 coworkers-participated in the study. The employees worked at a variety of different organizations in the southeast U.S., including technology, government, education, insurance, legal, financial, manufacturing, food service, and retail organizations. They averaged 25.7 years in age, 3.1 years of experience in the organization, and $48.9 \%$ worked full time (see Table 1 for additional demographics). The employees' supervisors were $63.5 \%$ male and 67.7\% Caucasian (18.1\% Hispanic or Latino/a, 6.3\% African American, and $2.4 \%$ Asian American), with an average age of 37.5 years and an average organizational tenure of 8.8 years. The employees' coworkers were $42.2 \%$ male and $59.1 \%$ Caucasian (21.3\% Hispanic or Latino, $7.9 \%$ African American, and 7.1\% Asian American), with an average age of 27.8 years and an average organizational tenure of 5.1 years.

We recruited participants using a snowball sampling procedure (e.g., Grant \& Mayer, 2009; Skarlicki \& Folger, 1997). Researchers sent an electronic message to 277 (51\% response rate) students in upper-level management courses at a university in the southeastern U.S. and provided them with the opportunity to partake in a study for extra credit. Students who worked at least 20 hours per week in a job were allowed to participate; otherwise, they were asked to invite a friend or family member to 
participate. The "focal employees" were instructed to visit a Web site to complete a survey and to send an electronic survey link to their supervisor and a coworker familiar with their work. Respondents were assured that their responses would remain confidential. Focal employees provided demographic and other information as well as responses to items from two scales measuring the propensity to morally disengage. Coworkers and supervisors provided ratings for the unethical work behaviors of the focal employee.

The propensity to morally disengage. Employees completed the 8item propensity to morally disengage scale described in Study $1(\alpha=.90$ in this sample). Fit indices from a confirmatory factor analysis revealed an acceptable fit of the Study 5 data to a one-factor model $(\mathrm{CFI}=.96$, $\mathrm{NNFI}=.94$, RMSEA $=.12$, SRMR $=.05$ ).

Alternative measure of moral disengagement. We used Duffy and colleagues' measure (Duffy et al., 2005; Duffy et al., 2002; McFerran et al., 2010) as an alternative measure of the propensity to morally disengage. It is the only extant measure that was designed to measure the propensity to morally disengage in adults (rather than children, as in Bandura et al., 1996; or undergraduate students, as in Detert et al., 2008), without being focused on a specific type of audience, such as athletes (Boardley \& Kavussanu, 2007; Corrion et al., 2010) or computer hackers (Rogers, 2001). It is also the only measure of the propensity to morally disengage that taps this disposition in a workplace context, thus making it the strongest alternative to our measure. The measure has 15 items $(\alpha=.90)$.

Social desirability. Participants also completed the same 10-item measure of social desirability as in Studies 1-4 (Strahan \& Gerbasi, 1972), but in this study responses were measured on a 7-point scale ranging from strongly disagree to strongly agree $(\alpha=.81)$.

Dependent variable. We collected data on employees' unethical work behavior from two sources, their immediate supervisor and a coworker. Because there is no validated survey measure of employee unethical behavior, we selected items from two extant measures of undesirable work behavior-Robinson and O'Leary-Kelly's antisocial work behavior scale (1998) and Bennett and Robinson's organizational deviance scale (2000) - that most clearly represent unethical organizational behavior. Rather than relying solely on our own judgments, we obtained ratings from a sample of 29 individuals with graduate-level management training-including 16 faculty who teach and research in the area of business ethics. We asked them to rate how unethical each of the 26 work behaviors on these two extant scales ( 7 from the antisocial behavior scale and 19 from the organizational deviance scale) is. These raters were told that although all of the 26 behaviors are clearly 
undesirable, not all are necessarily unethical according to the definition of unethical behavior as actions that cause direct harm to another individual or that violate widely accepted moral norms in society. Respondents then rated-using a 10-point scale ranging from $1=$ not unethical in the least to $10=$ extremely unethical - how unethical they considered each of the 26 antisocial and deviance items. We then created a 7-item measure of "unethical work behavior" using the items that received an average rating of 8.0 or higher. $^{2}$ The mean "unethicality" of these seven items was 8.37 versus, by contrast, 5.33 for the 19 items not used.

The seven items selected for this measure of unethical work behavior are: "Falsifying a receipt to get reimbursed for more money than you spent on business expenses" $(M=9.31, S D=1.00)$, "Discussing confidential company information with an unauthorized person" $(M=8.59, S D=$ $1.84)$, "Damaging property belonging to my employer" $(M=8.25, S D=$ 1.76), "Taking property from work without permission" $(M=8.24$, $S D=1.17)$, "Saying or doing something to purposely hurt someone at work" $(M=8.17, S D=1.81)$, "Using an illegal drug or consuming alcohol on the job" $(M=8.03, S D=2.01)$, and "Making ethnic, religious, or racial remarks at work" $(M=8.03, S D=1.80)$. These items indeed seem different from an ethics perspective compared with excluded items such as, "Spending too much time fantasizing or daydreaming instead of working" $(M=4.04, S D=1.86)$ and "Griping with coworkers" $(M=$ 3.07, $S D=1.79)$.

We then calculated, using the main sample, separate supervisor- $(\alpha=$ $.93)$ and coworker- $(\alpha=.93)$ rated employee unethical behavior scales by taking an average of that rating source's responses to the seven items about the focal employee's unethical work behavior. Supervisors and coworkers reporting the frequency with which they had observed the focal employee engage in each of the unethical behaviors, ranging from $1=$ never to $7=$ very often.

\section{Results}

As expected, the two measures of the propensity to morally disengage are highly correlated $(r=.77, p<.01)$. However, despite this, the data fit a two-factor CFA model that loads the two measures' items onto separate latent factors $\left(\chi^{2}=518, d f=225\right)$ better (chi-square difference test significant at $p<.001)$ than a one-factor model that forces all (23 of) the propensity to morally disengage items to load together $\left(\chi^{2}=747\right.$,

\footnotetext{
${ }^{2}$ As a robustness check, we ran all the same analyses reported in this section using a second 11-item measure of unethical work behavior that instead uses a cutoff of 7.0 or higher for item inclusion. The results are substantively unchanged.
} 
TABLE 8

Incremental Validity of the Propensity to Morally Disengage Over Other Predictors of Unethical Work Behavior (Study 5)

\begin{tabular}{|c|c|c|c|c|}
\hline & \multicolumn{2}{|c|}{$\begin{array}{c}\mathrm{DV}= \\
\begin{array}{c}\text { Supervisor-reported } \\
\text { employee unethical } \\
\text { behavior }\end{array}\end{array}$} & \multicolumn{2}{|c|}{$\begin{array}{c}\text { DV = Coworker-reported } \\
\text { employee unethical } \\
\text { behavior }\end{array}$} \\
\hline & Model 1 & Model 2 & Model 3 & Model 4 \\
\hline Social desirability & -.08 & -.08 & .06 & .06 \\
\hline $\begin{array}{l}\text { Alternative moral } \\
\text { disengagement } \\
\text { measure }\end{array}$ & $.43^{* *}$ & .22 & $.44^{* *}$ & .07 \\
\hline $\begin{array}{l}\text { Propensity to } \\
\text { morally } \\
\text { disengage }\end{array}$ & & $.27^{*}$ & & $.49^{* *}$ \\
\hline$R^{2}$ & .22 & .25 & .16 & .26 \\
\hline$\Delta R^{2}$ & & $.03^{*}$ & & $.10^{* *}$ \\
\hline
\end{tabular}

Standardized coefficients are presented. $N=128$ (supervisors), $N=129$ (coworkers). ${ }^{* *} p<.01,{ }^{*} p<.05$.

$d f=230)$. The two measures correlate similarly with supervisor-reported unethical behavior $(r=.47, p<.01$ for the new, shorter measure, and $r=.46, p<.01$ for the Duffy et al. measure). However, the new, shorter measure of the propensity to morally disengage is more strongly correlated with coworker-reported unethical behavior $(r=.52, p<.01)$ than the alternative (Duffy et al.) measure $(r=.41, p<.01)$. The alternative measure is more strongly correlated with social desirability $(r=-.46, p$ $<.01)$ than our new measure $(r=-.33, p<.01)$ as well.

To test Hypothesis 4, we examined the variance in supervisor- and coworker-reported employee unethical behavior accounted for by our new propensity to morally disengage measure beyond that explained by the alternative measure of moral disengagement and socially desirable response tendencies. As shown in Model 1 of Table 8, the alternative measure of the propensity to morally disengage explains a significant amount of variance in employee unethical behavior when our new measure is absent. However, the coefficient for the alternative measure becomes nonsignificant (see Model 2, Table 8) when the new measure of the propensity to morally disengage is added to the equation. In support of Hypothesis 4 , the variable for the new propensity to morally disengage scale ( $\beta=$ $.27, p<.05$ ) explains an additional $3 \%$ of the variance in supervisor-rated employee unethical work behavior even after accounting for an alternative measure of the propensity to morally disengage. 
This same pattern of results emerges when using coworker ratings of unethical work behavior as the dependent variable, though here the incremental value of the new measure is much greater. As shown in Table 8 , the alternative measure of the propensity to morally disengage is initially a significant predictor of coworker-rated employee unethical behavior (Model 3) but ceases to be when our new measure of the propensity to morally disengage is added to the equation (see Model 4). Again in support of Hypothesis 4, the variable for the new propensity to morally disengage scale $(\beta=.49, p<.01)$ explains an additional $10 \%$ of the variance in coworker-rated employee unethical work behavior even after accounting for an alternative measure of the propensity to morally disengage. This finding is particularly impressive because coworkers may be in a significantly better position than supervisors to know about the various types of employee unethical behavior assessed here, as presumably employees are more motivated to hide these behaviors from supervisors.

In both Models 2 and 4 (in Table 8), the standardized coefficients for the new measure are larger than the coefficients for the alternative measure, another means of comparing the relative importance of the two measures in the prediction of unethical workplace behavior (Combs, 2010). Finally, when models (not presented here) are run including our measure of the propensity to morally disengage and social desirability in the first step, and the alternative measure in the second step, in neither case does adding the alternative measure explain a significant additional proportion of the variance in unethical behavior. Collectively, these results suggest that the new measure of the propensity to morally disengage is superior to the closest current alternative. ${ }^{3}$

\section{Discussion}

The set of studies presented here demonstrates the potency of individuals' propensity to morally disengage in the prediction of unethical organizational behavior and, in the process, makes two major contributions to the literature. First, our finding-across five different samples and using different dependent variables - that the propensity to morally disengage consistently emerges as a significant predictor of a wide range of organizationally relevant unethical behaviors, explaining additional variance above and beyond many of the major alternative individual difference antecedents, provides compelling evidence that morally

\footnotetext{
${ }^{3}$ We also ran all models described in Study 5 using as dependent variables the fulllength scales for antisocial workplace behavior (Robinson \& O'Leary-Kelly, 1998) and organizational and interpersonal deviance (Bennett \& Robinson, 2000). Results are similar results to those reported here (and are available from the first author).
} 
disengaged reasoning represents a critical factor in a wide range of unethical workplace behaviors.

Specifically, we demonstrated the predictive validity of the propensity to morally disengage beyond the explanatory power of (a) morally salient individual differences (Machiavellianism, moral identity, and empathy), (b) rational-deliberative constructs such as capacity for moral reasoning (cognitive moral development) and philosophical orientations (predispositions towards idealism and relativism), and (c) dispositional moral emotions (shame and guilt) across an array of unethical behaviors, including self-reported lying, cheating, and stealing; business-related unethical and self-serving decision making; and supervisor- and coworker-reported unethical employee behavior. In fact, compared to the numerous alternative predictors we selected and controlled for based on theoretical and meta-analytic evidence, our measure of the propensity to morally disengage is the strongest and most consistent predictor of multiple unethical organizational outcomes in the studies reported here. ${ }^{4}$

Notably, most of the relationships between the propensity to morally disengage and other constructs in its nomological network were assessed for the first time, thus additionally contributing new knowledge about the morally relevant individual difference correlates of the propensity to morally disengage. As expected, the propensity to morally disengage correlates positively with Machiavellianism and relativism; negatively with moral identity, empathy, cognitive moral development, idealism, and dispositional guilt; and is not significantly correlated with dispositional shame. Given these findings, we suggest that future theoretical models, empirical studies, and intervention efforts seeking to understand and reduce unethical outcomes include the propensity to morally disengage as a valuable explanatory construct.

Our second major contribution is the development and validation of a parsimonious, adult-oriented, easily administered measure of the propensity to morally disengage. Despite increasing interest in this construct in recent years (Aquino et al., 2007; Detert et al., 2008; Duffy et al., 2005; Moore, 2008b), research has been hampered by the lack of a consistently used, short, reliable, and clearly valid measure of the propensity to morally

\footnotetext{
${ }^{4}$ Note that in designing our studies to assess the incremental validity of our propensity to morally disengage measure we chose the baseline controls (which are entered as a block in the regressions) on the basis of theory and meta-analytic evidence. As shown in the correlation tables for studies 2,3 , and 4 (Tables 4, 6, and 7), the majority these variables are significantly correlated at the bivariate level with the dependent variable in these studies. The bivariate relationships between cognitive moral development, idealism and relativism, and the unethical organizational outcome in Study 3 are not significant, which makes the incremental validity of the propensity to morally disengage demonstrated in this study more limited.
} 
disengage. Given consistent calls to improve measurement in the field of behavioral ethics (Mayer et al., 2009; Tenbrunsel \& Smith-Crowe, 2008; Treviño et al., 2006), we believe this contribution warrants special note. We followed rigorous best practices for new measure development (Clark \& Watson, 1995; Hinkin, 1995; John \& Benet-Martinez, 2000) to construct and validate - using multiple samples diverse in respondent background and demographics - a parsimonious and psychometrically sound measure of the propensity to morally disengage in adults that should prove useful in a broad spectrum of future research with adults. The measure is consistent with Bandura's theory of moral disengagement as a general process and taps, in a unifactorial scale, the eight theorized mechanisms that sever the link between internalized moral standards and unethical behavior.

In our analyses, we were also able to show that the new measure outperforms the best available alternative, and much longer, measure of the construct (McFerran et al., 2010). We also consistently controlled for respondents' tendency to respond in socially desirable ways, thereby ruling out potential concerns that our findings might be contaminated by social desirability bias. Further, to reduce concerns about respondent fatigue, common method bias, and uncertain direction of causality as much as possible, we collected data for Studies $2-4$ using two surveys each, with time separation of up to 1 month (Ostroff, Kinicki, \& Clark, 2002). And, in Study 5, we obtained ratings of unethical employee behavior from both supervisors and coworkers.

\section{Implications for Theory}

In the series of studies presented here, the propensity to morally disengage is a consistently stronger correlate of unethical decisions and behavior than a wide array of other theoretically relevant predictors and consistently explains variance in unethical decisions beyond these other predictors in multivariate analyses. Theoretically, this suggests that Bandura's self-regulatory approach, and in particular, his articulation of the cognitive means by which people's self-regulation process can be thwarted, provides a strong and useful foundation for understanding and predicting unethical decisions and behavior in organizations. Thus, behavioral ethics researchers should consider how other individual difference constructs might fit within a social cognitive self-regulation framework. For example, future research is needed to better understand how moral traits and emotions, such as empathy and guilt, relate to self-regulatory processes and morally disengaged reasoning. Such affective dispositions may be part and parcel of anticipatory self-regulation that prevents morally disengaged reasoning from occurring and/or may take effect and thus counter the personal acceptance of such reasoning as it reaches 
consciousness. Similarly, deliberative ethical reasoning strategies (as driven by cognitive moral development or idealism/relativism) will likely only be used if moral disengagement has not occurred before such deliberation actually begins. Though the actual process of moral disengagement remains poorly understood, it may well occur prior to a number of these other processes, thus preempting them and helping to explain why the propensity to morally disengage is consistently a stronger predictor of unethical decisions and behavior in our studies.

Other constructs within the nomological network of the propensity to morally disengage might also be further considered from a self-regulation perspective. Machiavellianism, for example, may reflect either insufficient internalization of widely shared moral standards or the internalization of counternormative standards that often dominate decision making when two or more standards conflict. In the first "Wall Street" movie, Gordon Gekko (with, for example, his "greed is good" speech) appears to be a strong Machiavellian who has internalized and is driven by self-interest rather than concern for others or fairness standards that are expected to have force in normally socialized individuals. In such a case, the propensity to morally disengage may be used to readily override more prosocial selfregulatory standards.

The social cognitive self-regulatory perspective may also provide theoretical insights if applied to some of the newer thinking and research in behavioral ethics. For example, much attention has been paid recently to less deliberative and more impulsive or intuitive models of ethical decision making (Haidt, 2001; Reynolds, Leavitt, \& DeCelles, 2010). Our focal construct - the propensity to morally disengage — seems consistent with and potentially valuable to research on these models because this way of thinking likely happens automatically and, to some extent, at a subconscious level. Individuals with higher propensities to morally disengage may in fact be those with the most developed "self-justifying systems" for rationalizing intuitively made decisions. All of the ideas proposed here must be further theoretically developed and tested. Our point is to suggest potential ways that behavioral ethics scholars might benefit from adopting this overarching theoretical framework and, where appropriate, our new scale for empirical testing of emergent hypotheses.

\section{Implications for Research}

Following Bandura, we conceptualized the propensity to morally disengage as an individual difference that represents a generalized cognitive orientation to the world. However, the propensity to morally disengage is not necessarily invariant across contexts or time (Paciello, Fida, Tramontano, Lupinetti, \& Caprara, 2008). Consistent with his broader 
social cognitive theory, and with most work on moral development (Bandura, 1986; Kohlberg, 1984), Bandura described moral disengagement as explicitly interactive, the result of the continued reciprocal influences of the individual, behavior, and the environment (Bandura, 2002). Thus, acknowledging that disengaging self-sanctions through morally disengaged reasoning may also be triggered by specific contextual factors (suggesting moral disengagement may also have a state instantiation) is consistent with Bandura's theory $(1999,2002)$. For example, specific moral disengagement mechanisms are most likely triggered by particular circumstances (e.g., displacement of responsibility in response to dominant authority figures). Researchers are beginning to investigate situationally motivated moral disengagement as triggered by unethical actions (e.g., Shu, Gino, \& Bazerman, 2011) or other aspects of a situation such as how much personal gain or harm to others is involved (e.g., Treviño, Detert, Sweitzer, \& Gephart, 2008). A next step will be to combine these approaches by simultaneously studying both dispositional and situational influences, and their possible interaction, on morally disengaged reasoning (see Cronbach \& Snow, 1977 for ideas on constructing research designs that capture both individual and situational variation). Research on moral disengagement that examines both the person and the situation simultaneously would capture more directly the interactionist nature that dominant theories agree characterize our moral selves (Bandura, 1990b; Treviño, 1986). Such approaches would also be consistent with thinking about many other individual differences (Hoyle \& Leary, 2009) and with theories describing how traits can be activated in particular contexts (Tett \& Burnett, 2003; Tett \& Guterman, 2000).

Overall, our theoretical approach and statistical results are consistent with Bandura's theorizing (Bandura, 1986, 1990a, 1990b, 1999, 2002) that the specific mechanisms that underlie the propensity to morally disengage represent a single higher-order construct. Nevertheless, future research may reveal that valid and reliable first-order measures can also be developed to tap the propensity to use specific moral disengagement mechanisms (e.g., attribution of blame) that would be useful for particular research contexts or questions. For example, it may be valuable to assess only diffusion of responsibility when studying teamwork or collective action, or just displacement of responsibility when studying unethical behavior stemming from the nature of authority relationships in work hierarchies. Or, researchers may wish to compare various specific moral disengagement mechanisms to see which predict the most unwanted behavior in particular contexts. Because we focused on moral disengagement as an overarching propensity, we did not set out to develop first-order mechanism scales, and we did not produce subscales that presently meet acceptable standards (e.g., reliabilities of .70 or higher). Nevertheless, we 
list all 24 items tested in Study 1 in Appendix A as a potential starting point for others who wish to pursue this research avenue.

Finally, this study and others have provided a great deal of information about the relationships between the propensity to morally disengage and many types of unethical behavior relevant to organizations as reported by the self or by employees' supervisors and coworkers. The linking here, in Study 5, of the propensity to morally disengage with supervisor and coworker reports of unethical work behavior is particularly impressive as it is likely a conservative test of what employees actually do (because many unethical behaviors are intentionally hidden, especially from authority figures). Nonetheless, future studies that link the propensity to morally disengage with objectively measured subsequent unethical behavior in actual work contexts would be particularly valuable.

\section{Implications for Practice}

As Combs notes, the relevance of an empirical effect found in research is often best understood in economic terms (2010). In our studies, the additional variance in an outcome measure accounted for by our propensity to morally disengage scale ranges from $3 \%$ to $10 \%$. At first blush, these effect sizes may seem to be of questionable practical value. Yet, given the enormous costs of unethical behavior to organizations and societies, we suggest that these results are actually very important. For example, $3 \%$ of the estimated $\$ 350$ billion that the U.S. government loses every year to tax evasion (U.S. Internal Revenue Service, 2010) is $\$ 10.5$ billion dollars, and 3\% of the $\$ 2.9$ trillion estimated to be lost annually to global fraud (Association of Certified Fraud Examiners, 2010) is \$87 billion dollars. Clearly these losses, and many others of similar size (e.g., those occurring as a result of employee or consumer theft), are anything but trivial.

The magnitude of the effect sizes found here for the propensity to morally disengage on unethical decision making relative to other dominant predictors in the behavioral ethics literature (noting that the effects for the propensity to morally disengage found here are beyond many other theoretically important influences) is also worth considering (Aguinis et al., 2010). In the Kish-Gephart et al. (2010) meta-analysis, the largest average effect size for any of the traditionally studied individual difference predictors of unethical behavior was for Machiavellianism at $\rho=$ .27 (across 11 studies and 2,290 individuals). If the effects from the four predictive validity studies in this paper are combined, the average corrected correlation between our new propensity to morally disengage and unethical outcomes (using the same calculation methods as used in the 
Kish-Gephart analyses, cf. Hunter \& Schmidt, 2004) is $\rho=.36 .^{5}$ Though this effect size only aggregates the effects of four studies and 857 individuals, it may be cautiously interpreted as suggesting that the propensity to morally disengage is the strongest individual difference predictor of unethical behavior identified to date.

The measure we developed in this study is also practically useful. It is short, easy to complete, and appropriate for general adult samples. The measure's consistently low correlation with the most commonly used social desirability measure allays concerns that individuals administered this measure for job-related purposes will simply provide "expected" responses. Thus, this measure may be useful in lieu of the much longer (100-plus items) and laborious administrations of more expensive commercial integrity tests (cf., Berry, Sackett, \& Wiemann, 2007). Administering the scale to all applicants but having those making hiring decisions blind to the results may allow organizations to determine over time how valuable this instrument is in predicting subsequent misbehavior and whether its use as a selection tool is warranted.

Organizations should also investigate whether morally disengaged thinking can be attenuated through intervention or training. The one study that has examined moral disengagement longitudinally found evidence that individual levels of moral disengagement are malleable to external influences over time (Paciello et al., 2008), which suggests that moral disengagement - even among those more predisposed toward such reasoning - may well be receptive to training interventions. Such interventions could have practical implications for organizations that are interested in reducing the harm caused by morally disengaged thinking. For example, if moral disengagement operates in ways similar to other cognitive biases (an empirical question), it could be quite beneficial to train employees to be on the lookout for certain modes of thinking (e.g., "I have to do it because my boss said so") so that they can catch themselves or others before unethical behavior occurs (Bazerman \& Tenbrunsel, 2011). One interesting question in this regard would be whether training focused on those with initially high propensities to morally disengage (who might learn how to lessen their own distorted thinking) or those with lower initial propensities (who might learn more easily to recognize it and intervene with others) is more effective in reducing the measurable harm done from moral disengagement.

\footnotetext{
${ }^{5}$ We thank Jennifer Kish-Gephart for her assistance with this analysis. Note that the $95 \%$ confidence intervals around the uncorrected meta-analytic correlations between unethical outcomes and (a) the propensity to morally disengage (uncorrected mean $r=.30, \mathrm{CI} .19$ to .41) and (b) Machiavellianism (uncorrected mean $r=.22$, CI .15 to .28) overlap, as would be expected given the theoretical and empirical relationship between the propensity to morally disengage and Machiavellianism.
} 
Organizations might also consider instituting a variety of measures designed to reduce the likelihood that morally disengaged reasoning goes unchecked. For example, leaders can use formal and informal means to increase individual accountability, making the displacement or diffusion of responsibility and the attribution of blame onto others feel less valid as justifications for behavior even among those with higher propensities to morally disengage. Leaders can likewise clearly encourage the use of ethical language and discourage the acceptance of euphemisms that cloud judgments. In addition, leaders can make harm to other stakeholders more real to employees so that dehumanization or blame for "bringing harm onto themselves" is less likely. Of course, only with careful research will we know whether these interventions are effective in minimizing moral disengagement in those most predisposed to do so or whether ultimately organizations are better off relying on careful selection and early screening mechanisms.

\section{Conclusion}

This paper's five complementary studies robustly demonstrate how individuals' propensity to morally disengage predicts multiple types of work-relevant unethical behavior. We offer a systematically developed, parsimonious, reliable, and valid new measure for assessing the propensity to morally disengage so that scholars and practitioners can use it to better understand and reduce unethical behavior. Collectively, our findings establish the pervasive predictive power of the propensity to morally disengage, illuminating the importance of this construct.

\section{REFERENCES}

Aguinis H, Werner S, Lanza Abbott J, Angert C, Park JH, Kohlhausen D. (2010). Customercentric science: Reporting significant research results with rigor, relevance, and practical impact in mind. Organizational Research Methods, 13, 515-539.

Ambrose M, Arnaud A, Schminke M. (2008). Individual moral development and ethical climate: The influence of person-organization fit on job attitudes. Journal of Business Ethics, 77, 323-333.

Aquino K, Reed A. (2002). The self-importance of moral identity. Journal of Personality and Social Psychology, 83, 1423-1440.

Aquino K, Reed A, Thau S, Freeman D. (2007). A grotesque and dark beauty: How moral identity and mechanisms of moral disengagement influence cognitive and emotional reactions to war. Journal of Experimental Social Psychology, 43, 385-392.

Ashforth BE, Anand V. (2003). The normalization of corruption in organizations. Research in Organizational Behavior, 25, 1-52.

Association of Certified Fraud Examiners. (2010). Global fraud study: Report to the nations on occupational fraud and abuse. Retrieved from www.acfe.com/rrtn.

Badaracco JL, Useem J. (2006). Conflict on a trading floor. Harvard Business School Case (9-394-060). Cambridge, MA: Harvard Business School Press. 
Bandura A. (1986). Social foundations of thought and action: A social cognitive theory. Englewood Cliffs, NJ: Prentice-Hall.

Bandura A. (1990a). Mechanisms of moral disengagement. In Reich W (Ed.), Origins of terrorism: Psychologies, ideologies, states of mind (pp. 161-191). New York, NY: Cambridge University Press.

Bandura A. (1990b). Selective activation and disengagement of moral control. Journal of Social Issues, 46, 27-46.

Bandura A. (1999). Moral disengagement in the perpetuation of inhumanities. Personality and Social Psychology Review, 3, 193-209.

Bandura A. (2002). Selective moral disengagement in the exercise of moral agency. Journal of Moral Education, 31, 101-119.

Bandura A, Barbaranelli C, Caprara GV, Pastorelli C. (1996). Mechanisms of moral disengagement in the exercise of moral agency. Journal of Personality and Social Psychology, 71, 364-374.

Bandura A, Caprara GV, Zsolnai L. (2000). Corporate transgressions through moral disengagement. Journal of Human Values, 6, 57-64.

Bazerman MH, Tenbrunsel AE. (2011). Blind spots: Why we fail to do what's right and what to do about it. Princeton, NJ: Princeton University Press.

Bennett RJ, Robinson SL. (2000). Development of a measure of workplace deviance. Journal of Applied Psychology, 85, 349-360.

Benson ML. (1985). Denying the guilty mind: Accounting for involvement in a white-collar crime. Criminology, 23, 583-607.

Berry CM, Sackett PR, Wiemann SA. (2007). A review of recent developments in integrity test research. PERSONNEL PSYCHOLOGY, 60, 270-301.

Bird FB. (1996). The muted conscience: Moral silence and the practice of ethics in business. Westport, CT: Quorum.

Boardley ID, Kavussanu M. (2007). Development and validation of the moral disengagement in sport scale. Journal of Sport and Exercise Psychology, 29, 608-628.

Bolinger D. (1982). Language: The loaded weapon. London, UK: Longman.

Brief AP, Buttram RT, Dukerich JM. (2001). Collective corruption in the corporate world: Toward a process model. In Turner ME (Ed.), Groups at work: Theory and research (pp. 471-499). Mahwah, NJ: Erlbaum.

Brown ME, Treviño LK. (2006). Ethical leadership: A review and future directions. The Leadership Quarterly, 17(6), 595-616.

Browne MW, Cudeck R. (1993). Alternative ways of assessing model fit. In Bollen KA, Long JS (Eds.), Testing structural equation models (pp. 136-162). Newbury Park, CA: Sage.

Caprara GV, Fida R, Vecchione M, Tramontano C, Barbaranelli C. (2009). Assessing civic moral disengagement: Dimensionality and construct validity. Personality and Individual Differences, 47, 504-509.

Cheung GW, Rensvold RB. (2002). Evaluating goodness-of-fit indexes for testing measurement invariance. Structural Equation Modeling, 9, 233-255.

Christie R. (1970). Scale construction. In Christie R, Geis FL (Eds.), Studies in Machiavellianism (pp. 10-34). New York, NY: Academic Press.

Christie R, Geis FL. (1970). Studies in Machiavellianism. New York, NY: Academic Press.

Chronbach LJ, Meehl PE. (1955). Construct validity in psychological tests. Psychological Bulletin, 52, 281-302.

Clark LA, Watson D. (1995). Constructing validity: Basic issues in objective scale development. Psychological Assessment, 7, 309-319.

Combs JG. (2010). Big samples and small effects: Let's not trade relevance and rigor for power. Academy of Management Journal, 53, 9-13. 
Corrion K, Scoffier S, Gernigon C, Cury F, d'Arripe-Longueville F. (2010). Développement et validation d'une échelle courte mesurant le désengagement moral en sport (ECDMS). L'Encéphale, 36, 495-503.

Cronbach L, Snow R. (1977). Aptitudes and instructional methods: A handbookfor research on interactions. New York, NY: Irgvington.

Crowne DP, Marlowe D. (1960). A new scale for social desirability independent of psychopathology. Journal of Consulting Psychology, 24, 349-354.

Davis MH. (1983). Measuring individual differences in empathy: Evidence for a multidimensional approach. Journal of Personality and Social Psychology, 44, 113126.

Detert JR, Treviño LK, Sweitzer VL. (2008). Moral disengagement in ethical decision making. Journal of Applied Psychology, 93, 374-391.

Deutsch M. (1990). Psychological roots of moral exclusion. Journal of Social Issues, 46, 21-25.

DeVellis RF. (1991). Scale development: Theory and applications. Newbury Park, CA: Sage.

Diener E. (1976). Effects of prior destructive behavior, anonymity, and group presence on deindividuation and aggression. Journal of Personality and Social Psychology, 33, 497-507.

Douglas T. (1995). Scapegoats: Transferring blame. New York, NY: Routledge.

Duffy MK, Aquino K, Tepper BJ, Reed A, O’Leary-Kelly A. (2005, November). Moral disengagement and social identification: When does being similar result in harm doing? Paper presented at the Academy of Management Annual Conference, Honolulu, Hawaii.

Duffy MK, Tepper BJ, O’Leary-Kelly A. (2002). Moral disengagement and antisocial behavior at work. Paper presented at the Annual Meetings of the Southern Management Association, Atlanta, GA.

Eisenberg N. (1986). Altruistic emotion, cognition, and behavior. Hillsdale, NJ: Erlbaum.

Eisenberg N. (2000). Emotion, regulation, and moral development. Annual Review of Psychology, 51, 665-697.

Eisenberg N, Miller PA. (1987). The relationship of empathy to prosocial and related behaviors. Psychological Bulletin, 101, 91-119.

Forsyth DR. (1980). A taxonomy of ethical ideologies. Journal of Personality and Social Psychology, 39, 175-184.

Gino F, Pierce L. (2009). Dishonesty in the name of equity. Psychological Science, 20, $1153-1160$.

Grant AM, Mayer DM. (2009). Good soldiers and good actors: Prosocial and impression management motives as interactive predictors of affiliative citizenship behaviors. Journal of Applied Psychology, 94, 900-912.

Greenberg J. (2002). Who stole the money and when? Individual and situational determinants of employee theft. Organizational Behavior and Human Decision Processes, $89,985-1003$.

Gross E. (1978). Organizational crime: A theoretical perspective. Studies in Symbolic Interaction, 1, 55-85.

Haidt J. (2001). The emotional dog and its rational tail: A social intuitionist approach to moral judgment. Psychological Review, 108, 814-834.

Haidt J. (2003). The moral emotions. In Davidson RJ, Sherer KR, Goldsmith HH (Eds.), Handbook of affective sciences (pp. 852-870). New York, NY: Oxford University Press.

Hinkin TR. (1995). A review of scale development practices in the study of organizations. Journal of Management, 21, 967-988. 
Hoffman ML. (2000). Empathy and moral development: Implications for caring and justice. Cambridge: Cambridge University Press.

Hoyle RH, Leary MR. (2009). Methods for the study of individual differences in social behavior. In Leary MR, Hoyle RH (Eds.), Handbook of individual differences in social behavior (pp. 12-23). New York, NY: Guildford.

Hu L, Bentler PM. (1999). Cutoff criteria for fit indices in covariance structure analysis: Conventional criteria versus new alternatives. Structural Equation Modeling, 6, $1-55$.

Hunter JE, Schmidt FL. (2004). Methods of meta-analysis: Correcting error bias in research findings. Thousand Oaks, CA: Sage.

Jackall R. (1988). Moral mazes: The world of corporate managers. New York, NY: Oxford University Press.

John OP, Benet-Martinez V. (2000). Measurement: Reliability, construct validation, and scale construction. In Reis HT, Judd CM (Eds.), Handbook of research methods in social and personality psychology (pp. 339-369). New York, NY: Cambridge University Press.

Jöreskog KG, Sörbom D. (2009). LISREL 8.8: User's reference guide. Chicago, IL: Scientific Software International.

Kelman HC. (1973). Violence without moral restraint: Reflections on the dehumanization of victims and victimizers. Journal of Social Issues, 29(4), 25-61.

Kelman HC, Hamilton VL. (1989). Crimes of obedience. New Haven: Yale University Press.

Kern MC, Chugh D. (2009). Bounded ethicality: The perils of loss framing. Psychological Science, 20, 378-384.

Kish-Gephart JJ, Harrison DA, Treviño LK. (2010). Bad apples, bad cases, and bad barrels: Meta-analytic evidence about sources of unethical decisions at work. Journal of Applied Psychology, 95, 1-31.

Kline RB. (1988). Principles and practice of structural equation modeling. New York, NY: Guildford.

Kohlberg L. (1969). Stage and sequence: The cognitive-developmental approach to socialization. In DA. Goslin (Ed.), Handbook of socialization theory and research (pp. 348-480). Chicago, IL: Rand McNally.

Kohlberg L. (1984). Moral stages and moralization: The cognitive developmental approach. In Kohlberg L (Ed.), The psychology of moral development: The nature and validity of moral stages (Vol. 2, pp. 170-205). San Francisco, CA: Harper \& Row.

Kramer M. (1990). The moral logic of Hizballah. In Reich W (Ed.), Origins of terrorism: Psychologies, ideologies, theologies, states of mind (pp. 131-157). Cambridge, UK: Cambridge University Press.

Lewis HB. (1971). Shame and guilt in neurosis. New York, NY: International Universities Press.

Marsh HW. (1987). The hierarchical structure of self-concept and the application of hierarchical confirmatory factor analysis. Journal of Educational Measurement, 24, 17-39.

Mayer DM, Kuenzi M, Greenbaum RL. (2009). Making ethical climate a mainstream management topic: A review, critique, and prescription for the empirical research on ethical climate. In Cremer DD (Ed.), Psychological perspectives on ethical behavior and decision making (pp. 181-213). Greenwich, CT: Information Age.

McAlister AL. (2001). Moral disengagement: Measurement and modification. Journal of Peace Research, 38, 87-99. 
McFerran B, Aquino K, Duffy M. (2010). How personality and moral identity relate to individuals' ethical ideology. Business Ethics Quarterly, 20(1), 35-56.

Milgram S. (1974). Obedience to authority: An experimental view. New York, NY: Harper \& Row.

Moore C. (2008a). Moral disengagement in processes of organizational corruption. Doctoral dissertation, University of Toronto, Toronto, Canada.

Moore C. (2008b). Moral disengagement in processes of organizational corruption. Journal of Business Ethics, 80, 129-139.

Opotow S. (1990). Moral exclusion and injustice: An introduction. Journal of Social Issues, 46(1), 1-20.

Osofsky MJ, Bandura A, Zimbardo PG. (2005). The role of moral disengagement in the execution process. Law and Human Behavior, 29, 371-393.

Ostroff C, Kinicki AJ, Clark MA. (2002). Substantive and operational issues of response bias across levels of analysis: An example of climate-satisfaction relationships. Journal of Applied Psychology, 87, 355-368.

Paciello M, Fida R, Tramontano C, Lupinetti C, Caprara GV. (2008). Stability and change of moral disengagement and its impact on aggression and violence in late adolescence. Child Development, 79, 1288-1309.

Paternoster R, Simpson S. (1996). Sanction threats and appeals to morality: Testing a rational choice model of corporate crime. Law and Society Review, 30, 549-583.

Pelton J, Gound M, Forehand R, Brody G. (2004). The moral disengagement scale: Extension with an American minority sample. Journal of Psychopathology and Behavioral Assessment, 26, 31-39.

Piaget J. (1965). The moral judgment of the child. New York, NY: The Free Press.

Rapoport DC, Alexander Y. (Eds.). (1982). The morality of terrorism: Religious and secular justification. Elmsford, NY: Pergamon Press.

Ray JJ. (1983). Defective validity of the Machiavellianism scale. Journal of Social Psychology, 119, 291-292.

Rest JR. (1986). Moral development: Advances in research and theory. Minneapolis, MN: University of Minnesota Press.

Rest JR. (1990). DIT manual. Minneapolis, MN: University of Minnesota Press.

Reynolds SJ, Leavitt K, DeCelles KA. (2010). Automatic ethics: The effects of implicit assumptions and contextual cues on moral behavior. Journal of Applied Psychology, $95,752-760$.

Robinson SL, O’Leary-Kelly AM. (1998). Monkey see, monkey do: The influence of work groups on the antisocial behavior of employees. Academy of Management Journal, $41,658-672$.

Rogers M. (2001). A social learning theory and moral disengagement analysis of criminal computer behavior: An exploratory study. Doctoral dissertation, University of Manitoba, Winnipeg, Canada.

Sakalaki M, Richardson C, Thépaut Y. (2007). Machiavellianism and economic opportunism. Journal of Applied Social Psychology, 37, 1181-1190.

Schlenker BR, Forsyth DR. (1977). On the ethics of psychological research. Journal of Experimental Social Psychology, 13, 369-396.

Schwab DP. (1980). Construct validity in organizational behavior. Research in Organizational Behavior, 2, 3-43.

Shao R, Aquino K, Freeman D. (2008). Beyond moral reasoning: A review of moral identity research and its implications for business ethics. Journal of Business Ethics, $18,513-540$.

Shu LL, Gino F, Bazerman MH. (2011). Dishonest deed, clear conscience: When cheating leads to moral disengagement and motivated forgetting. Personality and Social Psychology Bulletin, 37, 330-349. 
Shultz CJ. (1993). Situational and dispositional predictors of performance: A test of the hypothesized Machiavellianism structure interaction among sales persons. Journal of Applied Social Psychology, 23, 478-498.

Siegel JP. (1973). Machiavellianism, MBA's and managers: Leadership correlates and socialization effects. Academy of Management Journal, 16, 404-411.

Skarlicki DP, Folger R. (1997). Retaliation in the workplace: The roles of distributive, procedural, and interactional justice. Journal of Applied Psychology, 82, 434-443.

Strahan R, Gerbasi KC. (1972). Short, homogenous versions of the Marlowe-Crowne social desirability scale. Journal of Clinical Psychology, 28, 191-193.

Sykes GM, Matza D. (1957). Techniques of neutralization: A theory of delinquency. American Sociological Review, 22, 664-670.

Tangney JP. (1990). Assessing individual differences in proneness to shame and guilt: Development of the self-conscious affect and attribution inventory. Journal of Personality and Social Psychology, 59, 102-111.

Tangney JP. (1991). Moral affect: The good, the bad and the ugly. Journal of Personality and Social Psychology, 61, 598-607.

Tangney JP, Stuewig J, Mashek DJ. (2007). Moral emotions and moral behavior. Annual Review of Psychology, 58, 345-372.

Tangney JP, Wagner P, Gramzow R. (1989). The test of self-conscious affect (TOSCA). Fairfax, VA: George Mason University.

Tenbrunsel AE, Messick DM. (1999). Sanctioning systems, decision frames, and cooperation. Administrative Science Quarterly, 44, 684-707.

Tenbrunsel AE, Messick DM. (2004). Ethical fading. The role of self-deception in unethical behavior. Social Justice Research, 17, 223-236.

Tenbrunsel AE, Smith-Crowe K. (2008). Ethical decision making: Where we've been and where we're going. Academy of Management Annals, 2, 545-607.

Tett RP, Burnett, DD. (2003). A personality trait-based interactionist model of job performance. Journal of Applied Psychology, 88, 500-517.

Tett RP, Guterman HA. (2000). Situation trait relevance, trait expression, and crosssituational consistency: Testing a principle of trait activation. Journal of Research in Personality, 34, 397-423.

Treviño LK. (1986). Ethical decision-making in organizations: A person-situation interactionist model. Academy of Management Review, 11, 601-617.

Treviño LK, Detert JR, Sweitzer VL, Gephart J. (2008, August). Motivated moral disengagement: Dispositional and situational influences on ethical reasoning and behavior. Paper presented at the Academy of Management Annual Conference, Anaheim, California.

Treviño LK, Weaver GR, Reynolds SJ. (2006). Behavioral ethics in organizations: A review. Journal of Management, 32(6), 951-990.

U.S. Internal Revenue Service. (2010). Information reporting program advisory committee: Tax gap subgroup report. Retrieved from www.irs.gov/taxpros/article/ o, id=228971,00.html.

Vaughan D. (1996). The Challenger launch decision: Risky technology, culture, and deviance at NASA. Chicago, IL: University of Chicago Press.

Weaver GR, Treviño LK. (1999). Compliance and values oriented ethics programs: Influences on employee attitudes and behaviors. Business Ethics Quarterly, 9, 315-335.

Wrightsman LS. (1991). Interpersonal trust and attitudes about human nature. In Robinson JP, Shaver PR, Wrightsman LS (Eds.), Measures of personality and social psychological attitudes (Vol. 1, pp. 373-412). San Diego, CA: Academic Press. 


\section{APPENDIX A \\ Propensity to Morally Disengage Scale}

\section{Moral Justification}

It is okay to spread rumors to defend those you care about.* It is alright to lie to keep your friends out of trouble.*

Playing dirty is sometimes necessary in order to achieve noble ends.

\section{Euphemistic Labelling}

Taking something without the owner's permission is okay as long as you're just borrowing it.*

It's okay to gloss over certain facts to make your point.*

When you're negotiating for something you want, not telling the whole story is just part of the game.

\section{Advantageous Comparison}

Considering the ways people grossly misrepresent themselves, it's hardly a sin to inflate your own credentials a bit.*

Compared to other illegal things people do, taking something small from a store without paying for it isn't worth worrying about.*

Damaging property is no big deal when you consider that others are assaulting people.

\section{Displacement of Responsibility}

People shouldn't be held accountable for doing questionable things when they were just doing what an authority figure told them to do.* People cannot be blamed for misbehaving if their friends pressured them to do it.*

You can't blame people for breaking the rules if that's what they were taught to do by their leaders.

\section{Diffusion of Responsibility}

People can't be blamed for doing things that are technically wrong when all their friends are doing it too.*

It's okay to tell a lie if the group agrees that it's the best way to handle the situation.*

In contexts where everyone cheats, there's no reason not to. 


\section{Distortion of Consequences}

Taking personal credit for ideas that were not your own is no big deal.*

Walking away from a store with some extra change doesn't cause any harm.*

It is OK to tell small lies when negotiating because no one gets hurt.

\section{Dehumanization}

Some people have to be treated roughly because they lack feelings that can be hurt.*

It's okay to treat badly somebody who behaves like scum.*

Violent criminals don't deserve to be treated like normal human beings.

Attribution of Blame

People who get mistreated have usually done something to bring it on themselves.*

If a business makes a billing mistake in your favor, it's okay not to tell them about it because it was their fault.*

If people have their privacy violated, it's probably because they have not taken adequate precautions to protect it.

Items measured on a 7-point Likert scale ranging from strongly disagree to strongly agree.

Items in bold comprise the final 8-item measure. Items marked with * comprise the 16-item measure. 